\title{
Opportunities and Choices
}

\section{Chapter 2 of the synthesis volume}

\author{
Paul Collier and Stephen A. O’Connell ${ }^{1}$
}

\footnotetext{
${ }^{1}$ Oxford University and Centre for Study of African Economies; and Swarthmore College and Centre for Study of African Economies. This is a draft chapter for the synthesis volume of the African Economic Research Consortium's Explaining African Economic Growth project. We thank Catherine Pattillo, Lemma Senbet, Nicholas van de Walle, Jeffrey Williamson, Growth project editors and researchers, and seminar participants at the AERC, Harvard, Oxford, the IMF, and the World Bank for helpful comments.
} 


\section{Introduction}

Growth depends upon the interaction of opportunities and choices. A country, or an entire region, may fail to grow either because there are no opportunities, or because choices are made that preclude opportunities being taken. The stark phenomenon we are trying to understand is that for forty years Africa stagnated while other developing regions grew. This chapter attempts to explain this alarming phenomenon in terms of the distinctive opportunities open to the region and the distinctive choices which were made.

Before explanation comes description. The comparison of regional growth rates must surely seem a straightforward matter. In fact, especially for Africa, it is sensitive to apparently arcane choices. To date, in our view scholars have invariably got these choices wrong and so we must begin with a brief discussion of these issues.

The basic unit for reporting GDP and its growth is the nation: regional figures on GDP are built up from these observations at the level of the nation. The most widely cited regional growth rates come from the World Economic Outlook (WEO) of the IMF and the Global Economic Prospects (GEP) of the World Bank. In both cases, the regional figures are half-way houses on the road to estimates of the growth of global GDP. Necessarily, in such an approach, the growth rates of regional and global GDP are simply arrived at from the total level of GDP and its comparison with the previous year. This is equivalent to averaging the annual growth rates of each country weighted by the GDP of each country. Around half of the GDP of sub-Saharan Africa is generated by South Africa, so that this approach gives a huge weight to the growth performance of South Africa. While the approach is appropriate if the question concerns total African GDP, it can be highly misleading as a description of the growth experienced by the typical African.

The alternative common approach to reporting Africa's growth rate is the easy procedure of taking the simple average of the underlying national growth rates. However, just as Africa's 48 countries differ by GDP, with South Africa being the whale, so they differ by population, with Nigeria being the whale. The simple average is driven by a group of minnows that between them have both negligible population and negligible GDP. For some purposes the experience of each country is indeed equally important each country constitutes a 'natural experiment' in how opportunities and choices combine to determine growth, and so generates equivalently valuable information for analysis. But as a description of the region's experience, a simple average of country growth rates is clearly indefensible.

Our own approach is to weight the underlying national growth rates by the share of each country's population. While this will give us the wrong answer to the question of how Africa's GDP grew in aggregate, it will give a more accurate picture of the growth experienced by the typical African. For example, it assigns Nigeria its true importance as the home of one-in-five Africans. If the growth process fails in Nigeria that is indeed more important for Africans than if it fails in South Africa - though it is less important for global GDP. For the WEO and the GEP it is global GDP that is important; for our purposes it is the experience of Africans. We then compare per capita growth rates, decade-by-decade, for two groups: 43 African countries and 56 non-African developing countries. To our knowledge, such population-weighted growth rates have not previously been calculated. 


\section{Figure 1: Smoothed growth rates of real GDP per capita}

(countries with full set of observations)

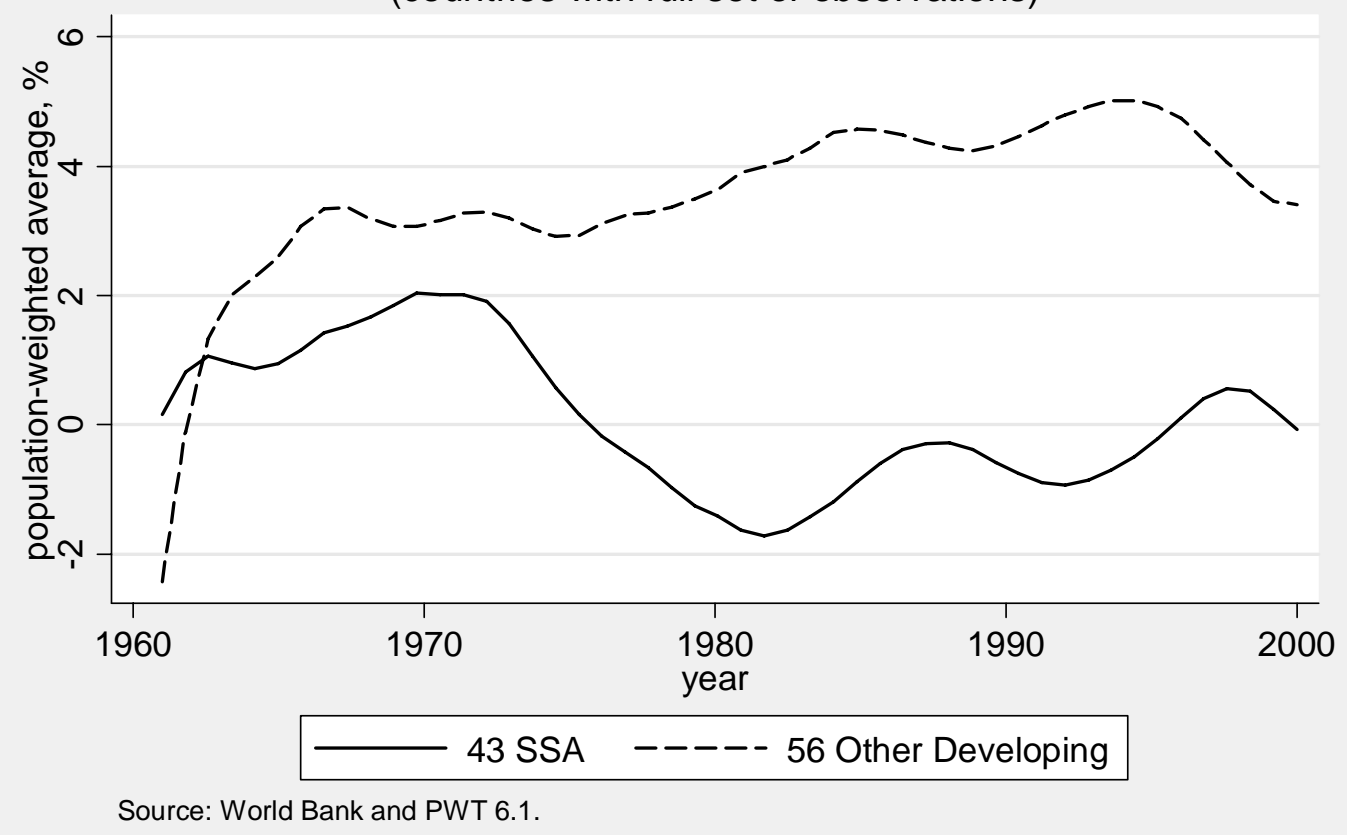

The results are shown for the forty years 1960-1999 in Figure 1, and by decade in Table 1. Over the entire period the average annual growth rate for Africa was a mere 0.13 percentage points. Taking into account the likely range of measurement inaccuracies, such a negligible growth rate is effectively zero. In other words, over the forty year period considered in this book the region stagnated. This absence of growth was distinctive to the region. For the rest of the developing world the per capita growth rate was higher than at any previous period in history at 3.63 percentage points.

Table 1. Population-weighted growth by decade.

\begin{tabular}{lccc} 
Decade & 43 SSA & $\begin{array}{c}\text { 56 Other } \\
\text { Developing }\end{array}$ & Difference \\
\hline $1960 \mathrm{~s}$ & 1.04 & 2.29 & 1.25 \\
$1970 \mathrm{~s}$ & 0.86 & 3.23 & 2.37 \\
$1980 \mathrm{~s}$ & -0.79 & 4.32 & 5.11 \\
$1990-2000$ & -0.46 & 4.46 & 4.92 \\
Total & 0.13 & 3.63 & 3.50 \\
\hline
\end{tabular}

The sample consists of all developing countries with full availability. See note to Table 2.

Thus, stagnation was divergence. Yet more seriously, the degree of divergence was accelerating. Whereas in the 1960s the difference in growth rates was only around one percentage point, since 1980 it has been around five percentage points. This 
widening difference was due both to growth acceleration in the rest of the developing world and to growth deceleration - to the extent of being negative - in Africa.

We now turn from description to analysis: why did Africa stagnate? In Section 2 we develop a simple classification of opportunities. We use this to build an estimate of the extent to which the differences between Africa's opportunities and those of other regions account for the observed difference in growth outcomes. In Section 3 we turn to policy choices. Building up from our 26 country case studies, we develop a typology of policy error: episodes when some major choice was clearly mistaken. We use this classification for all 48 African countries. In Section 4 we bring the two analyses together in an attempt to explain the divergence in growth rates as being due to the interaction of choices and opportunities.

\section{Africa’s Opportunities}

Opportunities for economic growth differ between countries. In this section we first develop a simple classification of opportunities. We then apply it to developing countries globally, bringing out the differences between Africa and the other developing regions.

\section{A basic classification of opportunities}

Two features of an economy that the literature suggests might influence its potential for growth are endowments and location. These form the basis for our classification.

\section{Endowments}

All developing countries share, to a degree, the characteristic of labor-abundance relative to developed countries, but they differ massively as to 'land'-abundance. Africa is a landabundant region in the literal sense that it has a large land area per inhabitant compared with all other developing regions. However, there are obviously enormous differences in the value of land depending upon characteristics such as rainfall and the natural resources that potentially can be discovered. In measuring the endowment of 'land' we therefore have a choice as to whether to use simply the area of land per inhabitant, or to introduce an economic concept based on the value of the resources contained in that land. The former approach has recently been adopted by Adrian Wood (2003), who argues that Africa is basically similar to Latin America, both being land-abundant in contrast to Asia. However, introducing a measure of economic value to this land has considerable advantages - without it, the average inhabitant of Niger, with a large acreage of landlocked, resource-free desert, will be characterized as much better endowed than the average inhabitant of Equatorial Guinea, living on a small island surrounded by oil. This is the approach taken here - we define 'land'-abundance in terms of the value of the 'rents' contained in the exports of primary commodities as a share of GDP. The rents reflect the excess of world prices over production costs, commodity-by-commodity. This approach has the disadvantage, as compared with land area, of being endogenous to the choices that a society makes. For example, in Chad the absolute value of the rents were endogenous because the investment needed for oil exporting was delayed due to internal conflict. More obviously, the share of rents in GDP depends upon the choices that 
influence the growth of non- 'land' GDP. The precise share of natural resource rents in GDP is thus clearly endogenous. To reduce this problem we classify according to a threshold: if an economy generates more than $10 \%$ of GDP from primary commodity rents it is deemed to be a 'natural resource' economy. Because prices of commodities fluctuate, potentially some economies flip backwards and forwards across this threshold year-to-year. Since our basic analysis is going to rest on political economy, with processes that do not switch on and off with such high frequency, we impose a somewhat greater degree of stability on the data. ${ }^{2}$

\section{Location}

Especially in the period since 1960 international trade has become increasingly important to the global economy. A potential impediment to participating in this trade is for a country to be landlocked. Sachs and his colleagues have pioneered research into this phenomenon which they have shown to be globally significant. Being landlocked is itself a very crude measure of the problem. For example, Switzerland is landlocked but this does not constitute an impediment, since its neighboring coastal countries - Germany, Italy and France - are not so much in the way of reaching its market, but themselves constitute its market. Hence, it might be more appropriate to nuance physical geography with an economic concept of distance to market. Initially, however, we take a simple geographic definition. Sachs has argued that even countries with a coastline can be effectively landlocked if their populations live a long way inland, for example, due to disease vectors. However, the great difference between a landlocked country and a coastal country whose population lives inland is that the latter has the potential for migration without legal impediment. Sachs has also emphasized the importance of other aspects of location, notably the incidence of disease, and Masters and McMillan (2001) have extended the concern to diseases of crops, showing the effect of the incidence of frost. Such refinements might indeed turn out to be critical. However, for the present we investigate how far a very simple classification can take us.

\footnotetext{
${ }^{2}$ Construction of the resource-rich variable: We classify a country as resource-rich starting in the first year the country satisfies the following three conditions.

- current rents from energy, minerals and forests exceed 5\% of GNI.

- a forward moving average of these rents exceeds $10 \%$ of GNI.

- the share of primary commodities in exports exceeds $20 \%$ for at least a 5 -year period following this initial year.

These criteria are meant to identify countries in which natural resource wealth is large enough to play a central role in economic management and in the interface of the country with global markets. Judgmental adjustments are required to "back-cast" this classification to the first part of the sample, because the resource rent data are available only since 1970 . We therefore back-dated the initial year to 1960 if the three criteria held in 1970 and the share of primary commodities in exports was already above $20 \%$ in 1965. If the three criteria held in 1970 and the share of primary commodities was above $20 \%$ in 1970 but below 20\% in 1965, we linearly interpolated the primary commodity share between 1965 and 1970 and back-dated the initial 'resource-rich' year to the first year the interpolated share exceeded 20\%. Additional judgmental adjustments were made for Equatorial Guinea (1996), Sierra Leone (1960) and Algeria (1960) based on country information.
} 


\section{Endowments and location in growth regressions}

The disaggregation according to endowment and location potentially generates four mutually exhaustive categories: landlocked resource-rich; landlocked resource-scarce; coastal resource-rich; coastal resource-scarce. However, there are both theoretical and empirical grounds for conflating the two resource-rich categories. From the perspective of theory, the rents on most natural resources are sufficiently high for the additional transport costs incurred by being landlocked are not a binding constraint upon their exportation. Whereas the Dutch disease effect of natural resource exports would tend to preclude diversification into manufactured exports even if the country was coastal. Hence, whether coastal or landlocked, a resource-rich country might be expected to have rather similar opportunities. This is borne out by the growth regression reported in Table 2. Here, all developing countries are classified into the mutually exclusive groups of coastal or landlocked, with the landlocked category as the default. All countries are then further divided into the mutually exclusive categories or resource-rich or resource-scarce.

Table 2. Geography and Growth: Disaggregating into Four Groups

Dependent variable: growth in real GDP per capita.

\begin{tabular}{lc}
\hline Variable & $\begin{array}{c}\text { Estimated coefficient } \\
\text { and standard error }\end{array}$ \\
\hline GCoastal & $1.542^{* * *}$ \\
& 0.275 \\
GCoastal*RR & $-0.592^{*}$ \\
& 0.329 \\
GLandlocked*RR & $1.397^{* *}$ \\
& 0.594 \\
\hline
\end{tabular}

$\mathrm{N}=3959$, Adjusted $\mathrm{R}^{2}=0.027$, RMSE $=6.405$, $\mathrm{F}=4.066(\mathrm{prob}>\mathrm{F}=0.000)$

$* \mathrm{p}<.1 ; * * \mathrm{p}<.05 ; * * * \mathrm{p}<.01$.

Notes: Estimation is by OLS for the full-availability developing-country sample (99 developing countries with at least 39 of 40 annual observations available). A full set of year effects is included. The labels "GCoastal" and "GLandlocked" refer to geographically-based, time-invariant coastal or landlocked status (with the exception of Ethiopia which changes in 1994, and Democratic Republic of Congo and Sudan, which we classify judgmentally as landlocked based on access to the coast). Here RR=resource-rich is a cross-cutting category defined as indicated in footnote 2 .

Globally, being coastal augments growth relative to being landlocked by over 1.5 percentage points. However, the interactions with resource abundance are profoundly different for coastal and landlocked economies. Resource abundance significantly reduces growth in coastal economies, whereas it significantly increases growth in landlocked economies. Hence, as theory predicts, resource abundance wipes out the growth opportunity otherwise inherent in a coastal location, replacing it with a lesser opportunity which is equally available whether the country is coastal or landlocked. In our subsequent analysis we therefore collapse the disaggregation into three groups: 
resource-rich (whether coastal or landlocked); coastal resource-scarce; and landlocked resource-scarce.

We first investigate whether the distinctions between resource-rich, non-resourcerich coastal, and non-resource-rich landlocked, are significant in a regression of growth over the relevant period 1960-2000, for developing countries as a whole (Table 3).

Table 3. Geography and Growth: Resource-Rich, Resource-Scarce Coastal, Resource-Scarce Landlocked

Dependent variable: growth in real GDP per capita.

\begin{tabular}{l|lll}
\hline \multirow{2}{*}{ Variable } & \multicolumn{3}{|c}{ Estimated coefficients and standard } \\
& \multicolumn{3}{|c}{ errors } \\
& $(1)$ & $(2)$ & $(3)$ \\
\hline Coastal & $1.542^{* * *}$ & $0.673^{* *}$ & $1.191^{* * *}$ \\
& 0.275 & 0.298 & 0.409 \\
Resource-Rich & $1.003^{* * *}$ & 0.319 & 0.715 \\
& 0.378 & 0.402 & 0.492 \\
Coastal*SSA & -- & -- & $-1.778^{* * *}$ \\
& & & 0.253 \\
Landlocked*SSA & -- & -- & $-1.082^{* *}$ \\
& & & 0.481 \\
Resource-Rich*SSA & -- & -- & $-1.458^{* *}$ \\
& & & 0.586 \\
SSA & -- & $-1.630 * * *$ & -- \\
& & 0.230 & \\
\hline N & 3959 & 3959 \\
Adjusted R ${ }^{2}$ & 0.028 & 0.041 & 3959 \\
RMSE & 6.404 & 6.361 & 0.040 \\
F & 4.772 & 5.253 & 6.362 \\
Prob>F & 0.000 & 0.000 & 0.000 \\
\hline
\end{tabular}

${ }^{*} \mathrm{p}<.1 ;{ }^{* *} \mathrm{p}<.05 ; * * * \mathrm{p}<.01$. Estimation is by OLS for the full-availability developing-country sample (see note to Table 2). All regressions include a full set of year effects.

Regression 1 finds that the distinctions are indeed significant. The resource-scarce coastal countries tended to growth markedly more rapidly than the resource-rich countries, which in turn grew much more rapidly than the landlocked resource-scarce countries. Since our focus will be on Africa, we next investigate whether controlling for these global differences, African countries had significantly distinctive growth. We first introduce a dummy variable for Africa: it is significantly negative (column 2). We then interact the dummy with each of the three geographic categories (column 3). All the interaction terms are significant and negative: within each category African countries underperformed the global average. However, beyond this there is a clear pattern. The underperformance was most severe for Africa's coastal resource-scarce economies, and least severe for Africa's landlocked resource-scarce economies. 
The contrasting distributions of the populations of Africa and other developing regions is shown in Table $4 .{ }^{3}$ The classification of countries changes from time to time, according to the value of the rents from primary commodity exports. Both Africa and other developing regions have had resource discoveries that have increased the proportion of the population living in resource-rich countries, but this has been much more pronounced for Africa.

Table 4. Population distribution by opportunity category.

\begin{tabular}{lccc}
\hline Group and decade & Coastal & Landlocked & $\begin{array}{c}\text { Resource- } \\
\text { rich }\end{array}$ \\
\hline 43 Sub-Saharan African countries & & \\
1960 s & 67 & 29 & 4 \\
1970 s & 47 & 29 & 23 \\
1980 s & 42 & 29 & 29 \\
$1990-2000$ & 35 & 35 & 30 \\
& & & \\
Total & 47 & 31 & 22 \\
\hline 56 Other developing countries & & & \\
1960 s & 96 & 1 & 3 \\
1970 s & 90 & 1 & 10 \\
1980 s & 88 & 1 & 11 \\
$1990-2000$ & 88 & 1 & 11 \\
Total & & & \\
\hline
\end{tabular}

The sample is all developing countries with full availability.

By the 1990s only 35\% of Africa's population was living in coastal, resourcepoor economies as opposed to $88 \%$ in the rest of the developing world. Resource-rich economies accounted for $30 \%$, as opposed to only $11 \%$ elsewhere. However, the most striking difference is in the proportion of the population living in landlocked, resourcepoor economies. Outside Africa this category was negligible - a mere one percent; within Africa it was $35 \%$. Because of these differences in opportunities, any systematic global differences in growth rates between the opportunity groups will give rise to differences between African and non-African growth rates.

\section{Differential growth performance and its decomposition}

We now compare the growth performance of the African region against that of the rest of the developing world, using this three-way disaggregation. To introduce an initial sense of how performance evolved, we break the information down by decade (Table 5).

\footnotetext{
${ }^{3}$ Appendix Table A1 provides the information for each country.
} 
Table 5. Growth differential by opportunity category and decade.

\begin{tabular}{|c|c|c|c|c|c|c|c|c|}
\hline Decade & \multicolumn{2}{|c|}{ Overall } & \multicolumn{2}{|c|}{ Coastal } & \multicolumn{2}{|c|}{ Landlocked } & \multicolumn{2}{|c|}{ Resource-Rich } \\
\hline & 43 SSA & $\begin{array}{c}56 \\
\text { Other }\end{array}$ & 43 SSA & $\begin{array}{c}56 \\
\text { Other }\end{array}$ & 43 SSA & $\begin{array}{c}56 \\
\text { Other }\end{array}$ & 43 SSA & $\begin{array}{c}56 \\
\text { Other }\end{array}$ \\
\hline $1960 s$ & 1.04 & 2.29 & 1.36 & 2.25 & 0.16 & 0.74 & 2.08 & 3.85 \\
\hline 1970s & 0.86 & 3.23 & 1.32 & 3.18 & -0.31 & 1.26 & 1.42 & 3.89 \\
\hline 1980s & -0.79 & 4.32 & -0.85 & 4.68 & 0.14 & 1.56 & -1.67 & 1.50 \\
\hline 1990-2000 & -0.46 & 4.46 & 0.27 & 4.74 & -1.30 & 1.91 & -0.42 & 2.47 \\
\hline \multirow[t]{2}{*}{ Total } & 0.13 & 3.63 & 0.50 & 3.79 & -0.36 & 1.40 & 0.29 & 2.89 \\
\hline & \multicolumn{2}{|c|}{ Difference } & \multicolumn{2}{|c|}{ Difference } & \multicolumn{2}{|c|}{ Difference } & \multicolumn{2}{|c|}{ Difference } \\
\hline 1960s & \multicolumn{2}{|c|}{1.25} & \multicolumn{2}{|c|}{0.89} & \multicolumn{2}{|c|}{0.58} & \multicolumn{2}{|c|}{1.77} \\
\hline 1970s & \multicolumn{2}{|c|}{2.37} & \multicolumn{2}{|c|}{1.86} & \multicolumn{2}{|c|}{1.57} & \multicolumn{2}{|c|}{2.47} \\
\hline 1980s & \multicolumn{2}{|c|}{5.11} & \multicolumn{2}{|c|}{5.53} & \multicolumn{2}{|c|}{1.42} & \multicolumn{2}{|c|}{3.17} \\
\hline 1990-2000 & \multicolumn{2}{|c|}{4.91} & \multicolumn{2}{|c|}{4.47} & \multicolumn{2}{|c|}{3.21} & \multicolumn{2}{|c|}{2.89} \\
\hline Total & \multicolumn{2}{|c|}{3.50} & \multicolumn{2}{|c|}{3.29} & \multicolumn{2}{|c|}{1.76} & \multicolumn{2}{|c|}{2.60} \\
\hline
\end{tabular}

The sample includes all developing countries with full availability. Growth rates are population-weighted; the overall differential corresponds to Table 1.

We start with the performance of the non-African developing countries. There were indeed large differences in growth rates between the three opportunity categories. The most successful of the three groups was the coastal, resource-poor economies. Their average per capita growth over the forty years was $3.78 \%$. Such rapid growth is without historical precedent and is cumulatively transforming. After forty years of such growth about the typical period of a working life - per capita incomes have increased by a factor of 4.6. ${ }^{4}$ The resource-rich economies were less successful despite their apparently more favorable opportunities. Their growth rates were one percentage point lower than the coastal, resource-poor economies. Nevertheless, growth was sufficient to be transforming over a single working lifetime. After forty years of such growth incomes have risen by a factor of 3.2. The least successful were the landlocked, resource-poor economies. The lack of both the basic opportunities identified in our classification evidently mattered. Indeed, it mattered a lot: growth was barely half that even of the resource-rich economies. For these economies growth was insufficient to be truly transforming over a working lifetime, but there was still progress: over forty years incomes rose only 75 percent.

In Africa, as in the rest of the world, the worst-performing group was the one with least opportunities - the landlocked, resource-scarce. In Africa this group were in gradual absolute decline. Cumulatively over the forty years, for the quarter of Africa's people living with these limited opportunities per capita incomes fell by nearly 15 percent. Whereas in absolute terms Africa's landlocked, resource-poor countries performed worst, in relative terms their performance was nevertheless much better than the other African

\footnotetext{
${ }^{4}$ Throughout the paper we use log differentials in growth calculations. The cumulative changes reported here are therefore given by $y_{t+40} / y_{t}=\exp (40 \cdot \mathrm{g})$, where $\mathrm{g}$ is the relevant average growth rate from Table 5.
} 
opportunity groups. The African resource-rich group diverged from the rest of the opportunity group at 2.6 percentage points per year. However, much the widest gap was that for the coastal, resource-poor economies. In Africa the group barely grew, and the growth gap with other regions was 3.28 percentage points. That Africa's coastal, resource-poor economies missed out on the transformation experienced elsewhere is the most important single factor in Africa's overall growth shortfall. Not only was this divergence substantial, it was widening. In other regions the growth of the coastal, resource-poor regions was accelerating. By contrast, in Africa it was decelerating. As a result the growth gap tended to widen drastically over the decades: $-0.93 ;-1.87 ;-5.51$; 4.45 .

Bringing together Tables 4 and 5, it is evident that African opportunities were heavily skewed towards the categories that in the rest of the world were least successful. The share of Africa's population living in the slowest-growing category - landlocked, resource-poor - was 35 times that of the other developing regions, and it also had treble the share living in the other slow-growing category - resource-rich. To what extent did this difference in opportunities account for the slower overall growth of Africa with which we started?

Table 6. Decomposition of growth differential by opportunity composition and opportunity-specific growth.

\begin{tabular}{|c|c|c|c|}
\hline \multirow[b]{2}{*}{ Decade } & \multirow[b]{2}{*}{ Difference } & \multicolumn{2}{|c|}{ Contribution of: } \\
\hline & & $\begin{array}{l}\text { Opportunity } \\
\text { composition }\end{array}$ & $\begin{array}{l}\text { Opportunity- } \\
\text { specific } \\
\text { growth } \\
\end{array}$ \\
\hline 1960s & 1.25 & 0.42 & 0.83 \\
\hline 1970s & 2.36 & 0.43 & 1.94 \\
\hline $1980 s$ & 5.11 & 1.48 & 3.63 \\
\hline 1990-2000 & 4.92 & 1.41 & 3.51 \\
\hline Total & 3.50 & 0.96 & 2.54 \\
\hline
\end{tabular}

Note: The formula is $g_{O}-g_{S}=\sum_{c=1}^{3}\left(\omega_{O c}-\omega_{S c}\right) \cdot g_{O c}+\omega_{S c} \cdot\left(g_{O c}-g_{S c}\right)$, where $g_{O}$ and $g_{S}$ are population-weighted growth in the "56 Other" and "43 SSA" regions and $\omega_{j c}$ is the share of category $c$ in population of region $j$. The regional population-weighted growth rates are from Table 1.

In Table 6 we decompose the difference in the overall growth rate between Africa and the rest of the developing world into that part due to the difference in their opportunity structures, and the differences in the opportunity-specific growth rates. The first column repeats the overall growth differential shown in Table 1. The second column shows that part due to differences in opportunity structure. This is arrived at by calculating the growth rate that Africa would have had were each of its opportunity 
groups to have had the growth rate of that opportunity group in other developing regions. That is we combine non-African opportunity-specific growth rates, with the African structure of opportunities. The effect of differences in opportunities is far from negligible - overall it accounts for a slower growth rate for Africa of 0.96 percentage points. Yet this is only $27 \%$ of the growth gap to be explained. Evidently, the main explanation for Africa's slow growth must look beyond this distinction between opportunities.

The crux of Africa's growth divergence is well illustrated in Figure 2 which shows the evolution of the three opportunity groups for Africa and other developing regions. We calculate these growth paths by setting real incomes equal to the relevant opportunity-specific regional averages in 1960, and then applying opportunity-specific regional growth rates for subsequent years. Outside of Africa, the rapid growth of the coastal resource-scarce economies, especially post-1980, took them by the end of our period comfortably into the middle-income range. Similarly, the resource-rich economies were able to grow out of poverty. The relatively few landlocked resource-poor economies still posed a development challenge, although even here if the trend continued by 2020 they would have reached the lower-middle-income level. In Africa, all three categories stay resolutely in the low-income category. On these trends, quite soon the low-income world would become synonymous with Africa.

Figure 2: Simulated Real GDP per Capita (countries with full set of observations)
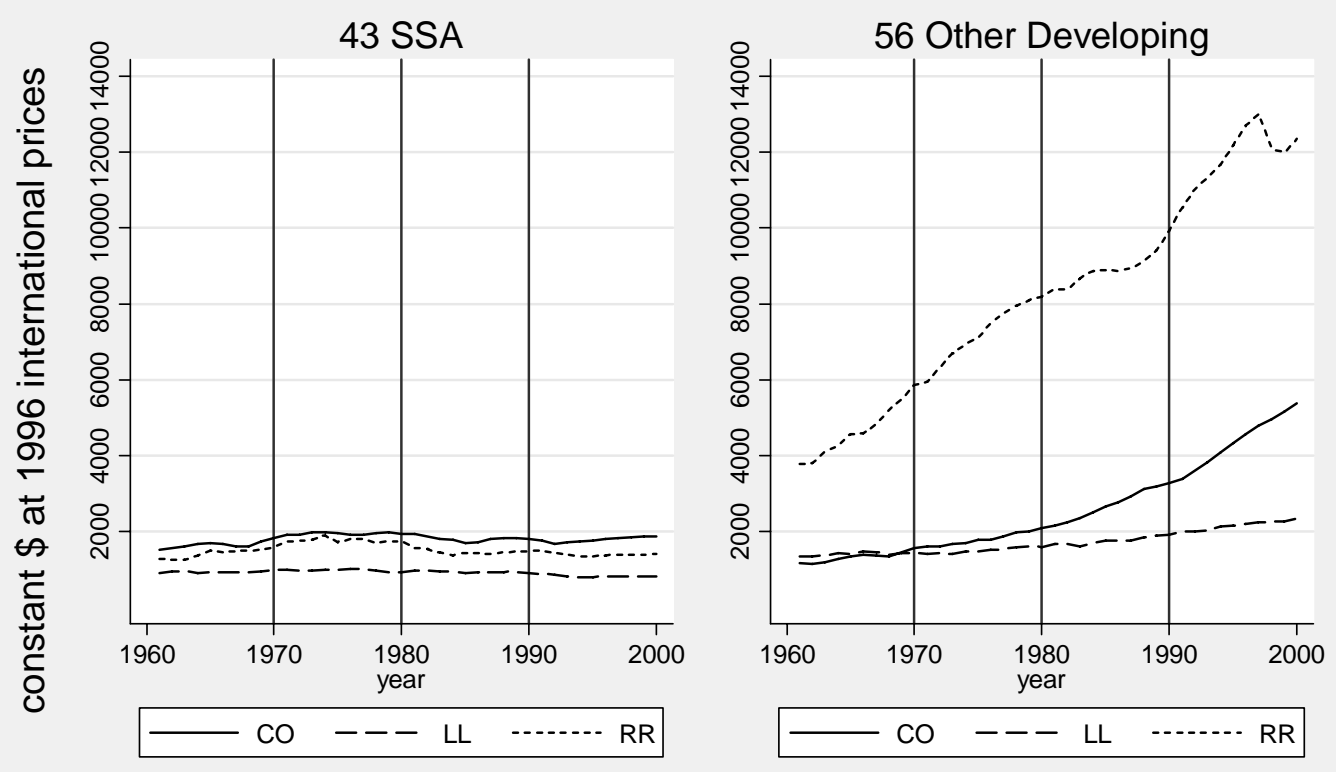

Source: PWT6.1, World Bank, and authors' calculations.

Note: The simulated paths show how GDP per capita would have evolved in each region and opportunity group if initial real incomes per capita had subsequently grown at observed region- and group-specific population-weighted annual growth rates. Note that the country composition of the group averages changes as the group composition evolves. 


\section{Key questions}

Africa's growth underperformance, on the above analysis, is proximately explained first and foremost by the failure of its coastal resource-scarce economies to replicate the growth pattern of other such economies as of around 1980. Additionally, it is relatively dependent upon natural resource economies which globally underperformed, and which in Africa performed markedly worse than the global average, though the pattern is very uneven both over time and between countries. Finally, Africa is the region with the largest share of landlocked resource-scarce economies which themselves somewhat underperformed relative to the already dismal global pattern.

These three proximate explanations generate three further questions. Why, as of around 1980 did coastal Africa not participate in the global pattern? Why did most of Africa's resource-rich economies fall short of the global average, and fall so far short of the successful pattern established by Botswana? Under what counterfactual would performance for Africa's landlocked resource-scarce economies have been significantly better?

It is now time to turn from opportunities to choices.

\section{Choices}

Africa is diverse. Although for the region taken as a whole over the forty year period that we consider there was stagnation, stagnation is not the norm. The average conceals enormous variation between countries, and also enormous variation over time. In this study our focus or units of observation are country-episodes, periods within a country that can broadly be considered as a unity for the purpose of understanding the growth experience. Since the overall growth experience is so dismal, our main concern is to understand episodes during which the growth process failed. However, our characterization of episodes is not defined by the growth outcomes, but rather by various dysfunctional political-economy configurations which we refer to as syndromes. The core of our study is to understand the overall growth failure in terms of four distinct syndromes, each of which accounts for growth failures in particular countries at particular times. The syndromes are not exhaustive of African experience. We do not attempt to force experience into the syndromes. Rather, in reviewing the accounts provided by our 26 case studies it became apparent that although no single overarching account of Africa's growth failure could be sustained, neither was each country's experience entirely unique. Our identification of four groups of syndromes came out of this review of our case study histories: some patterns became evident.

Having identified the syndromes to which African countries appear to have been prone, we then carefully reviewed each country's forty-year history with the country authors, to establish whether and when its experience is well-described by one or other of these syndromes. Some countries never experience any of the syndromes; others are characterized by more than one syndrome at the same time. Where a country episode was characterized by multiple syndromes it became a matter of judgment whether one of them was of overriding importance, or whether to understand the growth outcome multiple syndromes needed to be taken into account. Hence, some episodes feature in two or more chapters in our syndrome-specific analysis of Part II. In a final step, we reviewed the 
economic histories of 22 additional African countries in order to extend the syndrome classification to all of Sub-Saharan Africa.

The syndromes are not intended to be exhaustive of the ways in which growth can fail. Rather, they represent salient episodes of purposive failure attributable to human agency within the society, whether by leaders, governments or groups outside government such as rebel movements. A country may avoid these syndromes yet fail to grow, for example because it is unlucky in being hit by shocks, or because it is very badly endowed. We will of course be considering such explanations of the growth failure, and indeed sometimes they are central to understanding growth outcomes, but they are not included in our syndromes. Similarly, because our syndromes are defined by the choices of key actors rather than by growth outcomes, in principle a country episode might be characterized by one of our syndromes and yet experience sustainable growth. However, where this happens, unless there is some manifest lucky event, our characterization of the behavior pattern as a syndrome must be called into question. A behavior pattern within which several countries achieved sustainable growth could not reasonably be regarded as a syndrome.

We now discuss the syndromes. They fall into four major groupings of behavior: regulatory, distributive, inter-temporal, and state breakdown, and we consider them in turn. Appendix Table A2 provides the full classification for 48 countries.

\section{Regulatory syndromes}

Most African countries became independent at a time when socialist and communist strategies of economic development were fashionable. In Chapter 3 we discuss in detail the nature of such influences on African policy choices - in effect, why some of the syndromes were particularly common in Africa. Here we simply recognize that as a matter of fact many African countries adopted socialist or communist strategies of development. Our concern here is purely with the consequences of these choices for growth. The core of socialist and communist economic strategies was the regulation of economic activity, the ownership of productive enterprises by the state, and an industrialization strategy modeled, at least loosely, on that of the USSR and pursued behind high trade barriers financed through the taxation of exports. Additionally, at the level of political institutions, socialism and communism at least in Africa were used to justify one-party states. While this was common to both socialist and communist strategies, there were substantial differences in the extent to which regulation and state ownership were applied. While there is a continuum of the intensity of these economic regimes the differences along the continuum are sufficiently pronounced for it to be useful to distinguish between what we term 'hard controls' - in effect something close to the full communist vision, - and 'soft controls', where some parts of the economic would be regulated and some nationalized, but in which the ambition or efficacy of the policies was much more moderate. For example, in a 'hard control' regime such as Congo Brazaville, or Tanzania 1973-85, the banks and other 'commanding heights' of the economy would be nationalized, and virtually all private economic activity subject to regulations which substantially changed behavior through price controls and investment licensing. In a 'soft control' regime such as Zambia 1963-91, substantial parts of the economy - such as the banks - remained private, and price controls, although significant, 
were less pervasive. Just as there an element of judgment as to where along a continuum it is best to distinguish between hard and soft control regimes, so it is a matter of judgment where soft control regimes stop and other types of economic strategies start. In the 1960s planning was so fashionable that virtually all states had five-year plans. Similarly, virtually all states controlled some prices, or at least passed legislation which notionally set controlled prices. For example, Kenya had some price and interest rate controls, and regulated some aspects of internal agricultural trade, and Malawi had major state and quasi-state enterprises. By the standards of the 1990s these policy stances look quite interventionist. Yet we judge them to be markedly less interventionist than the strategies pursued in states such as Zambia and so do not include them in our category of 'soft controls'. Even the softest of the 'soft control' states involves regulation and state ownership outside the range found in the European social-market economies. To summarize, we have two types of regulatory syndrome - soft and hard control regimes. Each of these was quite common in Africa. If we take as our measure of exposure to syndromes the number of years in which any country in our sample experienced them, we find that between them the two variants of the regulatory syndrome accounted for around $35 \%$ of African economic history during 1960-2000. The soft control regime was about twice as common as the hard control regime.

\section{Redistributive syndromes}

We now turn to the second type of syndrome which concerns policies towards the redistribution of income between ethno-regional groups. Around $44 \%$ of African economic history during our period is characterized by this syndrome. All governments intervene in order to redistribute income between households, most commonly from richer to poorer. This is not our concern. Rather, we regard as potentially damaging for growth those situations in which the basic units of redistribution are ethno-regional. However, not all such redistributions are dysfunctional. Growth can potentially be damaged both by errors of commission and errors of omission.

We begin with errors of commission: the power of the state is used to redistribute substantial amounts of income from one ethno-regional group to another, and this has side-effects which reduce growth. For example, public revenues might be used to benefit a particular group rather than to provide public goods. This can adversely affect growth because some of the public goods that are neglected are capital goods. Another channel by which growth is adversely affected is if high costs are inflicted upon the economy in order to raise the revenues that are needed to finance redistribution. A third channel is if large-scale redistribution between ethnic groups so inflates the returns to power that substantial resources are devoted to the struggle to gain power - the concept known as 'rent-seeking'.

Conversely, errors of omission occur if the state fails to redistribute between ethno-regional groups in a situation in which such redistribution would be growthenhancing. One such situation is if one ethnic group is so much poorer than the other that the ordering is almost lexicographic: virtually all members of one ethnic group are poorer than those in the other. In such a situation there are reasonable grounds for expecting redistribution between ethnic groups to raise growth, for example because households in the poorer group are credit constrained. Another situation in which inter-ethnic 
redistribution can raise growth is if it pre-empts a strategy of violence on the part of the poorer ethnic group. In the absence of a voluntary transfer, the rational strategy for a poor-but-strong group may be to use violence to enforce a transfer. Pre-emptive redistribution can then be cost-effective even for the victim group because it avoids the costs of violence.

The first type of ethno-regional redistribution has been common in Africa during our period. An example of such an episode would be Kenya under President Moi. During this long episode an alliance of minor, and relatively poor, regions held power and used it to redistribute from the rich and previously favored region of Central Province and Nairobi. An example of how growth was sacrificed was the telecommunications strategy. The post office was used to create employment for the Kalenjin, the ethnic group at the core of President Moi's constituency, and to ensure the profitability of the post office it was cross-subsidized from telecommunications in a merged enterprise. In turn, to maintain the public telecommunications business profitable, competition in telecommunications was circumscribed, resulting in a service that was both bad and high cost. Since globally good telecommunications was becoming regarded as an essential feature of an environment conducive for growth, this ethnic transfer program thus inflicted high costs on the economy.

At the extreme end of ethno-regional redistribution, we find 'looting'. By this we mean a situation in assets, whether private or public, are stripped outside the context of the rule of law and due process. Often this is done by a leader and his small entourage who run the government for their personal financial advantage. In such a polity power will necessarily become highly concentrated because the leader cannot expect his objective to be widely shared. The power amassed by the head of state then becomes used to generate opportunities for personal wealth. Even were the dictator confident that his family would remain in power in perpetuity, such a concentration of power would be likely to affect growth adversely. However, personal rule is unlikely to be sustainable beyond one generation and since the dictator and his family are likely to recognize this, the inter-temporal aspects of the looting syndrome are similar to those of elite end-games to be discussed below. Long term growth of the economy is of little value to the dictator because he does not expect to benefit from such growth. Indeed, to the extent that growth would strengthen the position of actors other than the dictator and his entourage, it might weaken his hold on power. Further, because power is concentrated and the objective for which that power is used is so malign, other private actors can have little confidence that their legitimate interests will be respected. Few African leaders have been entirely altruistic or indeed entirely honest, and there is a continuum of personal corruption which at some point shades into the looting syndrome. However, we have reserved this classification for cases in which the personal aggrandizing behavior of the head of state was sufficiently dramatic to become a major explanation of macroeconomic performance. For example, we regard both Idi Amin in Uganda and General Abacha in Nigeria as not just clear cases of centralized personal power used for corrupt purposes, but that the economic history of these countries during their periods of rule cannot be understood without reference to this behavior.

Looting is not synonymous with dictatorship. Most dictators are not looters, and some democracies not only permit but actually induce looting. In Africa the most serious single episode of looting was indeed under the auspices of democracy, namely the 
Shagari regime in Nigeria, 1979-83. Nigeria accounts for a fifth of Africa's population and this period was the peak of the oil boom, potentially providing the country with massive finance for productive investment. This opportunity, probably the most important in Africa for our entire forty year period, was missed due to looting during democracy.

Whereas most of Africa's redistribution syndromes have been errors of commission, there have been some cases of errors of omission. The clearest case of a failure to redistribute between ethnic groups being directly dysfunctional for growth was South Africa under apartheid. A reasonable case can be made that redistribution would have enhanced the productivity of the poor ethnic group by more than it would have reduced the productivity of the richer group. Judgments as to failures to make preemptive redistributions are more difficult. An example is Chad prior to 1990. In Chad northerners tend to have a comparative advantage in military power and southerners in productive economic activity. Hence, unless the south redistributes to the north on a voluntary basis the north is liable to attempt to enforce redistribution through violent conflict. Post-1990 Chad established a sometimes fragile peace, partly due to such redistribution. Prior to 1990 the failure to adopt voluntary redistribution may have contributed to continuing conflict.

\section{Inter-temporal syndromes}

We now turn to the third type of syndrome in which the key errors were inter-temporal. Obviously, since our story concerns growth, or rather the failure of growth, in one sense all the syndromes involved inter-temporal errors. However, a useful distinction can be drawn between errors which had often inadvertent adverse consequences for growth - as in the control regimes - and errors which directly involved an undervaluation of the future. We estimate that inter-temporal syndromes account for around $18 \%$ of African economic history. We distinguish between two types of inter-temporal syndrome : anticipated redistributions, and unsustainable growth.

Anticipated redistribution occurs when an elite group anticipates a loss of power. For some reason it comes to believe that it will be unable to defend its level of income and, more particularly, its ownership of assets. The group therefore sees itself as in an 'end-game' in which its critical objectives are to amass wealth as rapidly as possible and to shift existing wealth abroad. The group may come to believe that its period in power is limited for various reasons, but the most likely is that it is if the elite are an ethnic minority faced by mounting popular pressure for political reform. Typically, the minority will have been in a position of entrenched power. For the period when it was confident of power it may have run a redistributive syndrome, or it may have managed the economy for the objective of economic growth - with income concentrated in the hands of the elite, growth delivers the elite disproportionate benefits. However, once the elite begins to doubt its ability to sustain itself in power the objective of growth become less attractive. The clearest example in Africa of such a switch in elite expectations occurs outside our sample - in Angola following the Portuguese revolution of 1974. Suddenly, the Angolan elite was confronted with a radically changed political situation in which in was evident that Portugal would not sustain the elite in power. This produced a dramatic economic exodus in which assets were shipped out of the country. Within our sample 
such end-games have been relatively rare, but important. The most substantial one is probably South Africa after around 1980. During the late 1970s political events in Southern Africa transformed prospects for continued Afrikaaner rule in South Africa. By the early 1980s the South African economy - largely controlled by white interests - had switched from a configuration of high investment and rapid growth to one of low investment and stagnation. We attribute this at least in part to an emerging fear on the part of the white elite that the returns on further investment would be subject to high taxation or other forms of redistribution. This state of affairs continued until the handover of power, and to an extent has continued even under ANC rule. A similar characterization applies, we think, to Burundi, where the Tutsi elite came to doubt its ability to hand onto power given that it formed such a small minority of the population. In the event, the elite did manage to hang onto power for a long time, but in heavily contested circumstances, so that the retention of elite power continued to look precarious.

The other inter-temporal syndrome we term 'unsustainable growth'. The concept of 'sustainable growth' is normally used in the context of environmental degradation for example, growth achieved by destroying forests. Although destroying forests is an unsustainable activity, it does not necessarily imply unsustainable growth. If the profits from deforestation are well-invested, the economy can simply move to some other activity at a sustainably higher level of income. Unsustainable growth occurs when a country fails to transform temporary income into permanent income, so that a period of good times is followed be a period of reversion. While such unsustainable growth is a missed opportunity, a pernicious variant is where the good times sow the seeds of subsequent destruction: the future is worse than if the temporary boom had never occurred. Environmental destruction indeed sometimes takes this form. However, there are two other routes to impoverishment that are particularly pertinent for our subsequent analysis: debt accumulation and irreversible expenditures. In the former the country amplifies temporarily favorable circumstances by borrowing internationally, but does not transform the borrowed resources into productive assets. In the latter, the country uses temporary income to lock into a pattern of expenditures which cannot easily be reversed, so that as income reverts to its former level damage is incurred by reducing expenditures which are more valuable than those which into which the country has become locked.

Africa has a high natural resource endowment per capita. Natural resources most obviously tempt a country into environmental unsustainability: depletion of the resource without adequate replacement with other assets. The depletion of Zambian copper is an example: the issue is not that the copper should have been left in the ground, - the resource depletion itself was clearly appropriate, - but that other assets should have been accumulated. However, natural resources also lure a country into unsustainability by other routes. The price shocks common to natural resources may induce periods of high income in which debt is accumulated and irreversible expenditure commitments are made. Nigeria during the oil boom of 1974-86 is the classic example of a temporary boom being geared up by debt accumulation. The oil boom was approximately doubled by debt accumulation. By the mid-1980s the country hit its borrowing constraint, coincident with a collapse in the oil price, so that real expenditure roughly halved over a very short period. Cote d'Ivoire during the 1970s was another example of unsustainable growth, in which public expenditure rose at an astonishingly fast pace, creating commitments, notably a government payroll, that could not be reduced during the 
following decade. A variant of unsustainable growth occurs where an unsustainable strategy is chosen in the context of a control regime. For example, in Congo Brazaville the oil boom was used to expand manufacturing industry behind heavy import protection. Statistically, this produced a phase of rapid growth, followed by a post-boom phase of equally rapid collapse, so that the economy appeared to have grown and then contracted. However, because the control regime heavily distorted domestic prices from opportunity costs, some of this growth was illusory. In effect, an unproductive activity was induced which was misleadingly recorded in the national accounts as productive. Hence, the growth might have been illusory rather than merely unsustainable.

The various forms of unsustainable growth are particularly pernicious because of their potential for confusion. Growth - often rapid growth - is coincident with the policy error, followed some years later by rapid decline. It is easy to mis-diagnose the decline as being due to errors made during the decline, and to see the growth phase as a success. A classic instance of such mis-diagnosis is the popular critique of the 'structural adjustment program' in Nigeria in the late 1980s. Because living standards were in radical decline during this period, the policies adopted during the period were blamed, despite the astonishing achievement that the growth of output was actually faster during this period than during the oil boom itself.

\section{State Breakdown}

The final syndrome is where the state is unable to maintain internal security. Again there is a continuum here from an inability to control crime, through to large-scale sustained rebellion. During our period Africa was increasingly affected by violent rebellion, although in our sample it accounts for only around $14 \%$ of African experience.

Nevertheless, the impact upon growth has been considerable. During civil war economies go into steep decline. For example, by the end of its period of conflict per capita incomes in Sierra Leone had fallen to only one third of their pre-conflict level. Further, many of these costs prove persistent - military spending remains high in post-conflict periods, and the social disruption, notably worsened health states, can last for a generation. Finally, many of the costs of a civil war spill over to neighbors. This can occur due to rivalries in military spending, to demand spillovers, migration and the disruption of transport routes. For example, the civil war in Mozambique approximately doubled the costs of international transport for Malawi, and the civil war in the Democratic Republic of the Congo prevented the Central African Republic from using its normal river route to the sea.

\section{Syndromes and Opportunities}

The population-weighted distribution of syndromes across the opportunities is shown in Table 7. Each person-year is an observation. For the coastal countries the most common syndrome was regulatory. Unsurprisingly, for the resource-rich the most common were redistributive and inter-temporal: there was a lot for the state to redistribute, and both the volatility of income and the scope for borrowing provided scope for inter-temporal error. Perhaps as a result of these greater opportunities, the resource-rich countries were overall 
much more prone to the syndromes. The landlocked were differentially prone to state breakdown, and differentially free of the inter-temporal syndrome.

Table 7. Frequency of syndromes by opportunity category.

\begin{tabular}{lcccc}
\hline & Coastal & Landlocked & $\begin{array}{r}\text { Resource- } \\
\text { Rich }\end{array}$ & Total \\
\hline $\begin{array}{l}\text { Distribution of people years } \\
\text { Percent }\end{array}$ & 44.4 & 30.9 & 24.7 & 100 \\
\hline $\begin{array}{l}\text { Frequency of Syndromes (\% of country/years) } \\
\text { Regulatory }\end{array}$ & 37.8 & 37.0 & 25.8 & 35.2 \\
Redistributive & 28.4 & 46.2 & 79.8 & 44.0 \\
Intertemporal & 15.1 & 4.8 & 46.7 & 18.2 \\
State Breakdown & 9.3 & 25.6 & 8.5 & 14.1 \\
Syndrome Free & 33.8 & 20.5 & 9.3 & 24.9 \\
\hline
\end{tabular}

Notes: The table uses all observations for 48 African countries, from the year of independence to 2000.

${ }^{*}$ Column sums exceed $100 \%$ because countries can exhibit multiple syndromes.

A more formal test of whether the opportunity groups differed in their proneness to each syndrome is set out in Table 8 which reports probit regressions with the landlocked category as the default. The landlocked resource-scarce countries are significantly less likely to be syndrome-free than their coastal counterparts, This is consistent with a longstanding hypothesis of Jeffrey Sachs that landlocked countries have worse policies because the returns to good policies are lower. They are also significantly more likely to suffer state breakdown than either of the other groups and less likely to suffer inter-temporal syndromes, perhaps because the societies are too poor to accumulate either assets or debts. As between the resource-rich and the coastal resource-scarce groups, the former are significantly more prone to the redistributive and intertermporal syndromes, and less prone to the regulatory. The greater proneness of the coastal resource-scarce group to the regulatory syndrome may reflect the greater relative importance of trade and the private sector in the economy: regulation is feasible and lucrative.

<Table 8, next page>

Table 9 summarizes how the prevalence of the syndromes in aggregate evolved decade-by-decade. During the 1990s the incidence of the syndromes declined sharply, but on average during the decade around $60 \%$ of Africans were still living in syndrome conditions.

$<$ Tables 9 and 10, next page $>$

Table 10 shows the evolution by opportunity group, taking into account the distribution of Africa's population. Although on average over the forty years the coastal, 
resource-poor economies were least prone to syndromes, this differed markedly over time. During the 1980s, when in the rest of the world the coastal, resource-poor countries started to take off, only $4 \%$ of the resource-scarce, coastal economies, and hence less than $2 \%$ of Africa's population, was living in those which were syndrome-free. Between the 1980s and the 1990s there were two dramatic changes. The coastal countries largely broke free of the regulatory syndrome, and the resource-rich countries largely broke free of the inter-temporal syndrome.

Table 8. Incidence of syndromes by opportunity group.

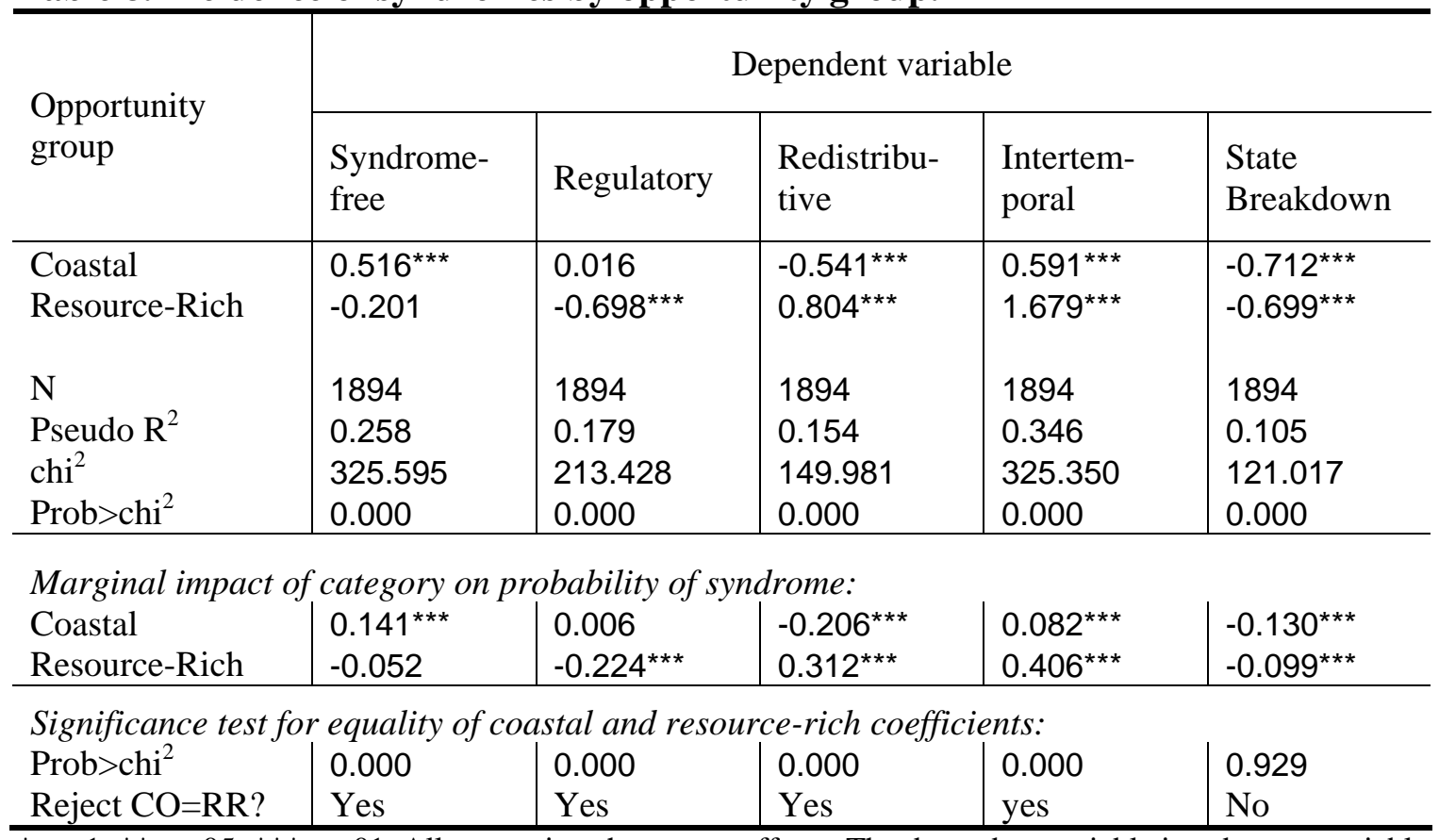

${ }^{*} \mathrm{p}<.1 ;{ }^{* *} \mathrm{p}<.05 ;{ }^{* * *} \mathrm{p}<.01$. All regressions have year effects. The dependent variable is a dummy variable for the occurrence of the syndrome. Landlocked is the omitted category. 
Table 9. Distribution of not-syndrome-free population by decade and opportunity category.

\begin{tabular}{l|c|c|c|c}
\hline \multirow{2}{*}{ Decade } & \multicolumn{3}{|c}{ Share of 48 -country SSA population exhibiting at least one } \\
syndrome
\end{tabular}

The table classifies all country/years for 48 SSA countries 1960-2000.

Table 10. Distribution of population by opportunity, syndrome and decade.

\begin{tabular}{|c|c|c|c|c|c|c|}
\hline \multirow{2}{*}{$\begin{array}{l}\text { Category } \\
\text { and Decade }\end{array}$} & \multirow{2}{*}{$\begin{array}{c}\text { Share of } \\
\text { category } \\
\text { in SSA } \\
\text { popula- } \\
\text { tion }\end{array}$} & \multicolumn{5}{|c|}{$\begin{array}{c}\text { Share of population in opportunity category } \\
\text { affected by: }\end{array}$} \\
\hline & & $\begin{array}{l}\text { Syn- } \\
\text { drome } \\
\text { free }\end{array}$ & $\begin{array}{c}\text { Regula- } \\
\text { tory }\end{array}$ & $\begin{array}{l}\text { Redis- } \\
\text { tributive }\end{array}$ & $\begin{array}{c}\text { Inter- } \\
\text { temporal }\end{array}$ & $\begin{array}{r}\text { State } \\
\text { Break- } \\
\text { down }\end{array}$ \\
\hline $\begin{array}{l}\text { Coastal } \\
\text { 1960s }\end{array}$ & 0.68 & 0.57 & 0.19 & 0.24 & 0.01 & 0.11 \\
\hline 1970s & 0.49 & 0.13 & 0.59 & 0.25 & 0.23 & 0.07 \\
\hline 1980s & 0.43 & 0.04 & 0.72 & 0.32 & 0.23 & 0.07 \\
\hline $1990-2000$ & 0.36 & 0.56 & 0.19 & 0.18 & 0.08 & 0.07 \\
\hline Total & 0.49 & 0.33 & 0.42 & 0.25 & 0.13 & 0.08 \\
\hline \multicolumn{7}{|l|}{ Llocked } \\
\hline 1960s & 0.29 & 0.20 & 0.37 & 0.33 & 0.00 & 0.33 \\
\hline $1970 \mathrm{~s}$ & 0.29 & 0.08 & 0.57 & 0.59 & 0.09 & 0.11 \\
\hline 1980s & 0.28 & 0.07 & 0.57 & 0.52 & 0.09 & 0.20 \\
\hline $1990-2000$ & 0.35 & 0.40 & 0.13 & 0.35 & 0.04 & 0.32 \\
\hline Total & 0.30 & 0.19 & 0.41 & 0.45 & 0.05 & 0.24 \\
\hline \multicolumn{7}{|l|}{ Resrich } \\
\hline 1960s & 0.04 & 0.84 & 0.08 & 0.00 & 0.00 & 0.08 \\
\hline $1970 \mathrm{~s}$ & 0.23 & 0.07 & 0.24 & 0.77 & 0.76 & 0.04 \\
\hline 1980s & 0.29 & 0.04 & 0.46 & 0.78 & 0.70 & 0.07 \\
\hline $1990-2000$ & 0.29 & 0.18 & 0.08 & 0.76 & 0.07 & 0.11 \\
\hline Total & 0.21 & 0.28 & 0.21 & 0.59 & 0.38 & 0.07 \\
\hline
\end{tabular}

Notes: The table covers all country/year observations between 1960 and 2000 for 48 countries in SSA. *The sum across all 5 columns can exceed 1 because a given country/year may exhibit more than one syndrome. 


\section{Consequences of the Syndromes for Growth}

\section{Possible effects of the syndromes on opportunities}

Between them these syndromes occupy around three-quarters of African experience. Potentially, this could imply that one quarter of the countries in Africa completely avoided the syndromes and three quarters were permanently stuck in them. In practice, few countries were permanently in these syndromes but even fewer escaped them altogether. In our sample, only Malawi, Botswana and Mauritius escaped all the syndromes for a sustained substantial period - more than two decades. All other countries at best had relatively brief episodes free from the syndromes. While growth was often reasonable during these syndrome-free episodes, they were too brief to raise incomes substantially.

The effect of the syndromes, or their absence, has to be evaluated against some counterfactual which reflects opportunities forgone.

The natural resource economies, of which Africa has a considerable number, are the most dependent upon governance. Natural resources generate large rents which accrue to government, and so the extent to which the rents are harnessed to growth depends critically upon government decisions. The sensitivity of performance to governance is well-illustrated by the contrast between Botswana and Sierra Leone. At the beginning of our period the two economies had approximately equal per capita incomes, and both were endowed with diamonds. By the end of our period the difference in per capita incomes was approximately ten to one, with Botswana having sustained one of the fastest growth rates in the world and Sierra Leone one of the fastest rates of decline. Recall that Botswana is one of the very few countries which we judge to have avoided all of the syndromes and this appears to have made a spectacular difference. It serves as an interesting counterfactual to the dismal growth performance of all the other natural resource economies that fell victim to one or other of the syndromes. Not all the syndromes are likely to have been equally damaging to natural resource economies. For such economies the key government decisions are inter-temporal - the rents extracted must be turned into productive investment either by the state itself or by the private sector. Hence, vertical and regional redistributions may not be particularly damaging in this context; indeed, regional redistributions might be desirable. Similarly, because the state in necessarily going to be large, soft control regimes may do relatively little damage.

The coastal economies without natural resources had the opportunity to follow the development path common in East Asia, by which countries integrated into the world economy through labor-intensive manufactured exports. Such exports are transactionsintensive with very low margins of profitability, and so performance is sensitive to economic policies. Success requires reasonable economic infrastructure and relative prices that come reasonably close to reflecting social opportunity cost. The opportunity for penetrating global markets deteriorated during our period because by the 1990s China (in manufactures) and India (in services) were so successful that there was considerably less room for other entrants to the market. Unfortunately, no mainland African coastal economy had policies conducive to manufactured exports for a sustained period prior to 1990. During the 1970s Cote d'Ivoire began to break into European markets for manufactures, but this was killed off by the end of the decade due to growing exchange 
rate overvaluation. The only African economy which succeeded in global manufactures was Mauritius - like Botswana a country we judge to have avoided all of the syndromes for an extended period. Mauritius is now by far the richest country in Africa in terms of per capita income, and so this again gives some insight into the opportunity cost of the syndromes in other coastal economies without natural resources. Unlike the natural resource economies, for manufactured exports the key decisions are not inter-temporal but rather concern the costs of doing business. Hence, for this group of economies we would expect that the control regimes - hard and soft - would be particularly damaging, as would a prioritization of redistribution - vertical or regional - over efficiency.

The landlocked economies without natural resources had dramatically worse opportunities for growth. Being landlocked they were precluded from significant entry into the global market for manufactures and without high-value natural resources they were left dependent upon agriculture. Globally, there is no example of such a country experiencing rapid growth during this period. One African country in this category we judge to have avoided all the syndromes for the entire 40 year period, namely Malawi. Yet its growth performance was modest. Uganda, another landlocked economy, performed well in the 1990s but to a substantial extent this was a recovery from previous collapse. Just as there is little upside potential for such economies, they may be relatively resilient to policy errors and predation. Peasant farmers have the option of retreating into subsistence and so defending their incomes. Hence, this group of economies may have lost least, both in absolute terms and relative to the counterfactual of potential growth, from their experience of the syndromes.

An Africa that had been free from the syndromes would thus, in our view, have looked very different not just in terms of overall growth, but in terms of the relative performance of countries. We would have expected to see the natural resource economies performing equivalently to Botswana, - in effect reaching lower-middle income status. We would have expected the coastal, resource-poor economies to have done better during our period those countries that succeeded in breaking into manufactured export markets experienced spectacular growth. There seems no natural obstacle to countries such as Kenya, Ghana, Tanzania, Cote d'Ivoire, Madagascar and Mozambique having similar growth experiences to Mauritius and Thailand. Such growth would have produced massive inequalities in income between African countries, with the landlocked economies without natural resources experiencing severe relative decline. This in turn would presumably have fueled substantial migration from the landlocked economies to the coast. This was indeed the pattern early in our period, before African growth decelerated. Malawi had a massive outflow of workers to South Africa, and Burkina Faso had a massive outflow to Cote d'Ivoire. In effect, Africa would have seen population movements similar to the migration to the coast that has occurred as a result of geographically skewed growth in China. Africa's relatively uniform lack of growth is thus, in our view, not the product of a uniform phenomenon, but rather the interaction of distinct syndromes with differential effects in different countries according to their opportunities. 


\section{How important were the syndromes?}

Just as we have investigated the contribution of differences in opportunities to accounting for the difference between African growth rates and those of other developing countries, so we can potentially do the same for the syndromes. In Table 11 we make an extreme 'working assumption' that we subsequently investigate, namely that other developing regions did not suffer from the syndromes. This assumption is not realistic, but it enables us to calculate an extreme bound as to how important the syndromes might have been. If the opportunity specific growth rates differ little between syndrome and syndrome-free periods, then as a matter of logic the syndromes cannot account for Africa's slow growth. Table 11 is constructed by taking as a counterfactual that without the syndromes each African opportunity group would have grown during a decade at the rate of the syndrome-free countries in the group in that decade. The first column takes from Table 6 the growth difference to be explained once we have controlled for Africa's distinctive opoprtunities. The second column shows the difference accounted for by the gap between the syndrome-free growth rate in each opportunity group in Africa, and that in other developing regions. The final column shows the contribution of the syndromes.

Taking the forty years as a whole, the syndrome effect is by far the most important of the three explanatory factors. It accounts for around half (52\%) of the overall growth differential. Taken together with the $27 \%$ accounted for by differences in opportunity structures, the residual accounted for by the difference between Africa's syndrome-free growth rate and that of other regions is only 0.72 percentage points. So, conditional upon the extreme assumption that the syndromes were unique to Africa they provide a lot of explanatory power. Decade-by-decade, the story is a little more complicated. The syndromes become less important, both absolutely and relatively in the 1990s.

Table 11. Contribution of syndromes to the growth differential.

\begin{tabular}{|c|c|c|c|}
\hline \multirow[b]{2}{*}{ Decade } & \multirow[b]{2}{*}{$\begin{array}{l}\text { Contribution of } \\
\text { opportunity } \\
\text { composition to } \\
\text { overall growth }^{\text {differential }}\end{array}$} & \multicolumn{2}{|c|}{ Of which: } \\
\hline & & $\begin{array}{l}\text { Differential } \\
\text { between } \\
\text { African } \\
\text { syndrome-free } \\
\text { growth and } \\
\text { growth in other } \\
\text { regions }\end{array}$ & $\begin{array}{l}\text { Within-Africa } \\
\text { syndrome } \\
\text { effect }\end{array}$ \\
\hline 1960s & 0.83 & -0.33 & 1.16 \\
\hline 1970s & 1.94 & -0.12 & 2.06 \\
\hline $1980 \mathrm{~s}$ & 3.63 & 1.16 & 2.46 \\
\hline $1990-2000$ & 3.51 & 1.63 & 1.88 \\
\hline Total & 2.54 & 0.63 & 1.91 \\
\hline
\end{tabular}


for $k=$ free or not free. Then SSA can fall short either through unfortunate composition or because of syndromes. Substituting for $g_{A c}$ in the earlier equation, we can decompose growth as

$g_{O}-g_{A}=\sum_{c=1}^{3}\left(\omega_{O c}-\omega_{A c}\right) \cdot g_{O c}+\omega_{A c} \cdot\left(g_{O c}-g_{A c f}\right)+\omega_{A c} \omega_{A c n} \cdot\left(g_{A c f}-g_{A c n}\right)$.

Table 11 is based on differences between Africa and other developing regions. A different approach is to analyze growth within Africa through regression analysis and estimate the effect of the syndromes. The effect of the syndromes in aggregate is shown in Table 12.

Table 12. Robust regressions controlling for shocks.

Dependent variable: growth in real GDP per capita.

\begin{tabular}{l|l|c}
\hline Variable & Country fixed effects not included & $\begin{array}{c}\text { Country fixed effects } \\
\text { included }\end{array}$ \\
\hline
\end{tabular}

A. Syndrome-free status not instrumented

\begin{tabular}{|c|c|c|c|c|c|c|}
\hline & (1) & (2) & (3) & (4) & (5) & (6) \\
\hline \multirow[t]{2}{*}{ Syndrome-free } & $2.076 * * *$ & $2.040 * * *$ & $1.890 * * *$ & $2.071 * * *$ & $2.162 * * *$ & $2.147 * * *$ \\
\hline & 0.241 & 0.332 & 0.249 & 0.318 & 0.303 & 0.366 \\
\hline \multirow[t]{2}{*}{ Partner growth } & $0.296 * * *$ & -- & $0.299 * * *$ & -- & $0.298 * * *$ & -- \\
\hline & 0.096 & -- & 0.094 & -- & 0.101 & -- \\
\hline \multirow[t]{2}{*}{ Dry year } & $-0.463 *$ & -0.174 & -0.309 & -0.224 & -0.265 & -0.252 \\
\hline & 0.264 & 0.259 & 0.250 & 0.306 & 0.333 & 0.328 \\
\hline \multirow[t]{2}{*}{ Coastal } & -- & -- & 0.476 & 0.008 & -- & -- \\
\hline & -- & -- & 0.364 & 0.306 & -- & -- \\
\hline \multirow[t]{2}{*}{ Resrich } & -- & -- & 0.050 & -0.254 & -- & -- \\
\hline & -- & -- & 0.415 & 0.357 & -- & -- \\
\hline $\mathrm{N}$ & 1492 & 1770 & 1492 & 1770 & 1492 & 1770 \\
\hline Pseudo R2 & 0.028 & 0.049 & 0.029 & 0.050 & 0.066 & 0.092 \\
\hline
\end{tabular}

B. Syndrome-free status instrumented

\begin{tabular}{|c|c|c|c|c|c|c|}
\hline & (7) & (8) & (9) & (10) & (11) & (12) \\
\hline \multirow[t]{2}{*}{ Syndrome-free } & $3.182 * * *$ & $5.100 * * *$ & $3.209 * * *$ & $5.196 * * *$ & $2.150 * *$ & 3.765 \\
\hline & 0.882 & 1.231 & 0.877 & 1.076 & 0.882 & $1.355^{* * *}$ \\
\hline \multirow{2}{*}{ Partner growth } & $0.335 * * *$ & -- & $0.234^{* *}$ & -- & $0.358 * *$ & -- - \\
\hline & 0.106 & -- & 0.112 & -- & 0.166 & -- \\
\hline \multirow[t]{2}{*}{ Dry year } & $-0.750 * *$ & -0.308 & $-0.784 * *$ & -0.431 & -0.653 & -0.283 \\
\hline & 0.339 & 0.319 & 0.340 & 0.357 & 0.441 & 0.463 \\
\hline \multirow[t]{2}{*}{ Coastal } & -- & -- & 0.164 & -0.236 & -- & -- \\
\hline & -- & -- & 0.471 & 0.344 & -- & -- \\
\hline \multirow[t]{2}{*}{ Resrich } & -- & -- & -0.067 & -0.087 & -- & -- \\
\hline & -- & -- & 0.578 & 0.487 & -- & -- \\
\hline \multirow{3}{*}{$\begin{array}{l}\mathrm{N} \\
\text { Pseudo R2 } \\
\text { Pseudo R2 from } \\
\text { stage 1 probit }\end{array}$} & 1183 & 1313 & 1183 & 1313 & 917 & 965 \\
\hline & 0.016 & 0.050 & 0.018 & 0.053 & 0.045 & 0.090 \\
\hline & 0.13 & 0.16 & 0.17 & 0.19 & 0.34 & 0.47 \\
\hline
\end{tabular}


Notes: Reported coefficients are from Least Absolute Deviation (LAD) regressions. Bootstrapped standard errors appear below the coefficient estimates $\left(* \mathrm{p}<.1\right.$; ${ }^{*} \mathrm{p}<.05$; *** $\left.\mathrm{p}<.01\right)$. In panel B we obtain instrumental variables estimates by running a stage 1 probit equation for syndrome-free status on all exogenous variables and all 3 instruments (rule by fear*ethnic fractionalization, socialist government, and a 1961-89 'cold war' dummy), and then estimating an LAD regression in stage 2 with syndrome-free replaced by the predicted probability from stage 1 . To obtain consistent standard errors in panel B, we bootstrap the full two-stage process, except in column 12 where there were insufficient observations to do so. (Thus in column 12 we report the bootstrapped standard errors from the second-stage regression. These were very close to the 'fully bootstrapped' standard errors in the cases of columns 7-11.) All regressions that exclude partner growth include a full set of annual dummy variables (period fixed effects). The $d r y$ year variable is a dummy variable equaling 1 when rainfall is more than one country-specific standard deviation below its country-specific long-run mean.

The regressions control for rainfall shocks and opportunity categories. The syndromes in aggregate are always highly significant. Depending on which of the six specifications is chosen, the syndromes are found to have lowered the growth rate by between 1.9 and 2.2 percentage points, which is compatible with the inference of Table 11 that the syndromes on average reduced growth by around 1.9 percentage points.

The results of Table 12A are potentially exposed to the critique that the syndromes are endogenous to economic performance. This could arise both because as researchers we may have inadvertently tended to categorize as syndromes those periods in which growth was low, or because periods of economic decline make a society more prone to various of the syndromes. We have tried to guard against the former, but the latter is undoubtedly a potential problem: for example, other research has established that periods of economic decline make African societies more prone to civil war (Miguel et al. 2004). We first test for endogeneity. This is not straightforward, since the regressions in Table 12 are quantile regressions and so not directly amenable to endogeneity tests. To perform such tests we therefore take a standard least-squares approach. Using a Hausman test we cannot reject that syndrome-free status is exogenous. However, because we have some a priori reason to be concerned about endogeneity, we adopt the approach of using instruments for the syndromes. Our instruments are taken from Chapter 11 where we indeed attempt to endogenize the syndromes. There we find that the syndromes collectively are made much more likely by the conjunction of ethnic fractionalization with an extreme form of dictatorship which we term 'rule-by-fear'. While this is more fully discussed in that chapter, here we note that it is the combination of these features, rather than their direct effects, that produce the syndromes. Ethnic fractionalization is evidently likely to be exogenous to the syndromes. While the political system itself might be endogenous, there is less reason to be concerned that the political system will only be endogenous in the context of ethnic fractionalization, so that the combination is a reasonable instrument for the syndromes. Our second instrument is the end of the Cold War, which is clearly exogenous to any developments in African politics. Our third instrument is a dummy variable for whether the head of state was avowedly 'socialist'. As we discuss in Chapter 4, African heads of state tended to get their ideas from prevailing international intellectual fashions rather than from the experience of their own societies. To a considerable extent, whether leaders had 'socialist' ideas did not derive from the recent economic performance of their own societies. Table 12B reports the results of using these three variables as instruments for the syndromes. The results are 
qualitatively unchanged: the syndromes are growth-reducing. Quantitatively, the effect of being syndrome-free is now even larger, with the effect on the growth rate ranging between two and five percentage points. Each of these variables is thus a reasonable instrument for the syndromes, although the first and third can potentially be questioned. Even when each of the three variables is used in turn as the sole instrument the results remain significant: being syndrome-free substantially augments growth. ${ }^{5}$

Given that the adverse effect of the syndromes appears to be robust we next investigate in what contexts they were particularly damaging to the growth process. For this we use quantile regressions, the results of which are reported in Figure 3 together with the bounds showing the 95\% confidence interval. Coefficients are estimated for each decile, the fifth decile corresponding precisely to the results reported in Table 12A. The quantile regression shows that the syndromes have different effects at different deciles of 'fortune'. For those countries with the very best fortune, avoidance of syndromes makes only a modest difference. For those with the worst fortune it makes an enormous difference. This implies that avoidance of the syndromes is a sufficient condition for avoiding growth collapses: if a country is syndrome-free even extreme ill-fortune is not ruinous for the growth process. Being syndrome-free is not a necessary condition for rapid growth of real GDP: if the country is sufficiently fortunate it can grow rapidly on a temporary basis, almost regardless of its choices. Thus, Equatorial Guinea has discovered so much oil that its GDP is growing despite continued predation by a narrow political elite; in Sudan, oil-based growth is temporarily robust to state breakdown. But poor choices sharply deteriorate the lower tail of growth outcomes, reducing the probability that an episode of rapid growth will be sustained over the medium to long term. Figure 3 implies that being syndrome-free is a necessary condition for sustaining rapid growth across periods of good and bad fortune.

\footnotetext{
${ }^{5}$ For reasons of space we do not report these results, but they are available upon request.
} 


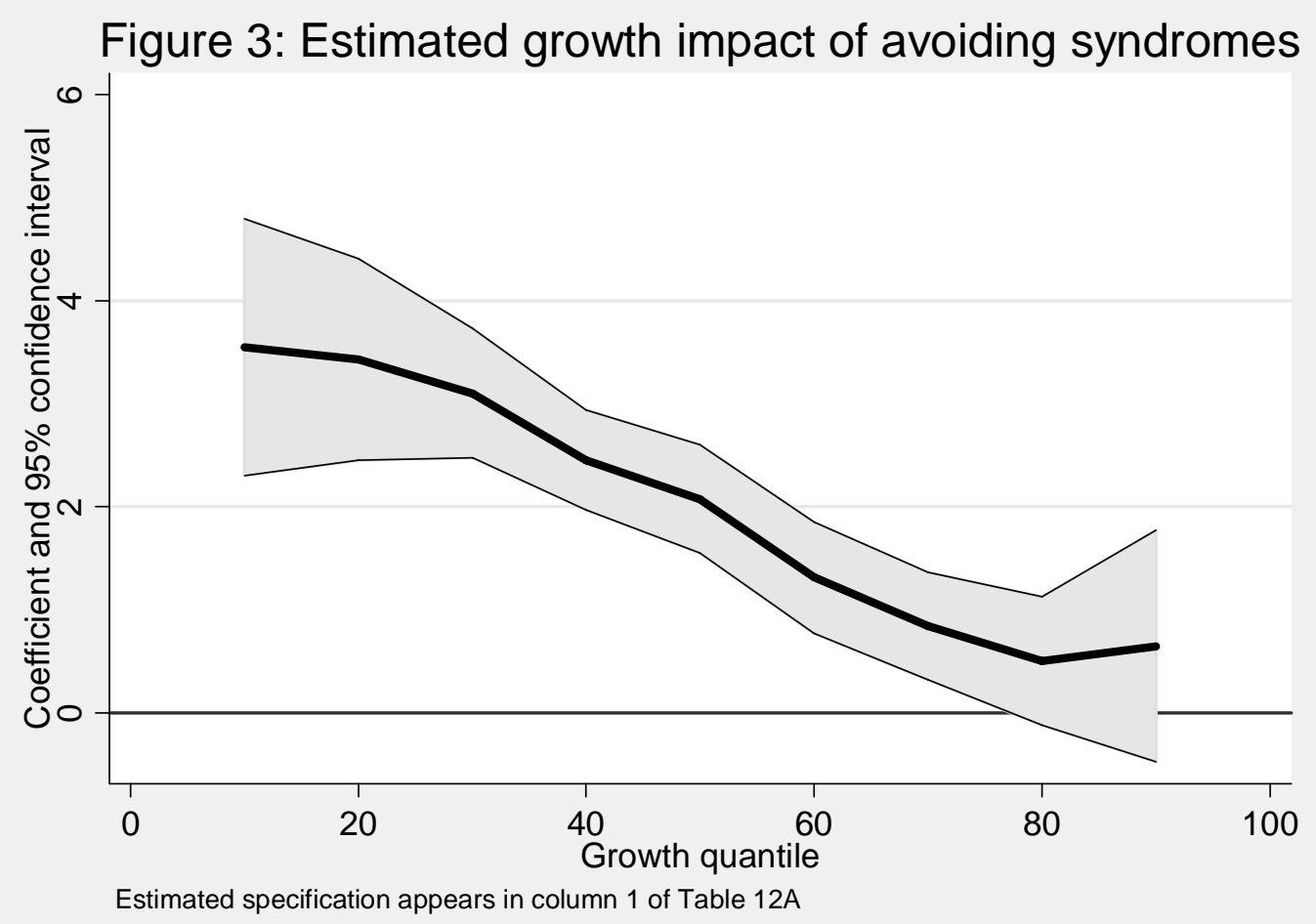

Hence, the intra-African evidence is consistent with that from the comparison of Africa with other regions, although the latter is currently predicated on the extreme assumption that the syndromes were unique to Africa.

In Table 13 we deepen the analysis by investigating differences between the syndromes, using the same approach as in Table 12. This reveals a large difference between the damage done by state breakdown and the other three syndromes, although all four are adverse. Depending on which of the six specifications is adopted, state breakdown reduces growth by between 1.8 and 2.0 percentage points. This is consistent with the global estimate of the effects of civil war of 2.2 percentage points off the growth rate (Collier, 1999). The other three syndromes each generate costs of around one percentage point off the growth rate.

Table 13. Robust regressions controlling for shocks: all syndromes.

Dependent variable: growth in real gdp per capita.

\begin{tabular}{l|llll|ll}
\hline \multirow{2}{*}{ Variable } & \multicolumn{3}{|c|}{ Country fixed effects not included } & \multicolumn{2}{c}{$\begin{array}{c}\text { Country fixed effects } \\
\text { included }\end{array}$} \\
& $(1)$ & $(2)$ & $(3)$ & $(4)$ & $(5)$ & $(6)$ \\
\hline Regulatory & $-0.972^{* * *}$ & $-0.900^{* *}$ & $-0.944^{* * *}$ & $-0.902^{* * *}$ & $-1.626^{* * *}$ & $-1.627^{* * *}$ \\
& 0.327 & 0.377 & 0.227 & 0.349 & 0.347 & 0.448 \\
Redistributive & $-0.983^{* * *}$ & $-0.783^{*}$ & $-0.952^{* *}$ & $-0.774^{* *}$ & -0.723 & 0.028 \\
& 0.262 & 0.403 & 0.415 & 0.354 & 0.735 & 0.474 \\
Intertemporal & -0.450 & -0.851 & -0.597 & -0.862 & -0.048 & -0.871 \\
& 0.604 & 0.708 & 0.531 & 0.532 & 0.837 & 0.575
\end{tabular}




\begin{tabular}{l|llll|ll} 
Breakdown & $-1.767^{* * *}$ & $-1.973^{* * *}$ & $-1.788^{* *}$ & $-1.963^{* * *}$ & $-1.872^{*}$ & $-1.986^{* * *}$ \\
\multirow{3}{*}{ Partner growth } & 0.650 & 0.443 & 0.696 & 0.424 & 0.989 & 0.643 \\
& $0.303^{* * *}$ & -- & $0.309 * * *$ & -- & $0.332^{* * *}$ & -- \\
Rainfall anomaly & 0.106 & & 0.098 & & 0.123 & \\
& $-0.425^{*}$ & -0.295 & -0.379 & -0.276 & -0.466 & -0.396 \\
Coastal & 0.231 & 0.231 & 0.366 & 0.200 & 0.314 & 0.325 \\
& -- & -- & 0.383 & -0.033 & -- & -- \\
Resrich & -- & -- & 0.378 & 0.392 & & - \\
& & & 0.230 & -0.036 & -- & - \\
\hline N & 1492 & 1770 & 1492 & 1770 & 1492 & 1770 \\
Pseudo R & 0.025 & 0.047 & 0.026 & 0.047 & 0.062 & 0.091 \\
\hline
\end{tabular}

Notes: See Table 12.

So far the only basis for the classification of syndromes has been our own subjective assessment, drawing on the accounts of the case studies. There are two ways of validating these classifications, objective evidence on policies and the subjective judgments of other informed observers. In Chapter 3 we follow the former route, assessing the extent to which our judgments correspond to objective information. Here we follow the alternative route and investigate whether our assessments correspond to other subjective judgments. The source we use for this is the annual rating system of World Bank economists, the 'Country, Policy and Institutional Assessment' (CPIA). The advantage of this rating system is that it is undertaken globally to a common standard and the series goes back to 1977. Hence, it is possible to compare Africa with other developing regions. Figure 4 shows the CPIA by region. The dashed line shows the average CPIA score over the period. The bold line shows the evolution of the CPIA year by year. Evidently, the policy and institutional environment has on average been judged to be worse in Africa than those of other developing regions.

We first investigate whether within Africa our classification of some periods as syndromes corresponds to markedly worse CPIA ratings: that is, within Africa, does our judgment correspond to those of other informed observers. In Table 14 we report annual panel regressions of the CPIA score on each syndrome. We control for year and for country fixed-effects. Table 14 shows that each of the syndromes other than the intertemporal is significant in explaining the CPIA score. The intertemporal syndrome is, indeed, marginally significant with the wrong sign. Recall that the main inter-temporal syndrome is unsustainable growth. We have already noted how pernicious this is from the perspective of whether the society correctly judges policy: during the upswing of this syndrome growth is rapid. While our disagreement with the CPIA may indicate that our judgment of these episodes is unduly adverse, it may instead indicate that during these misleading upswings the judgment of World Bank staff was systematically too favorable. From Table 14 we can conclude that with the notable exception of these episodes of unsustainable growth, our intra-African distinctions are largely shared by other observers. 
Figure 4: CPIA by region, $1977-2000$

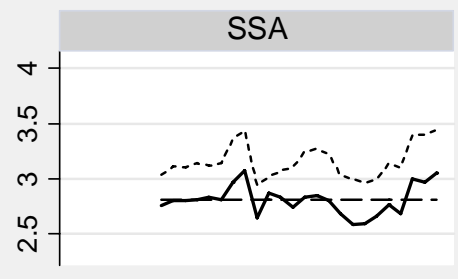

LAC SASIA

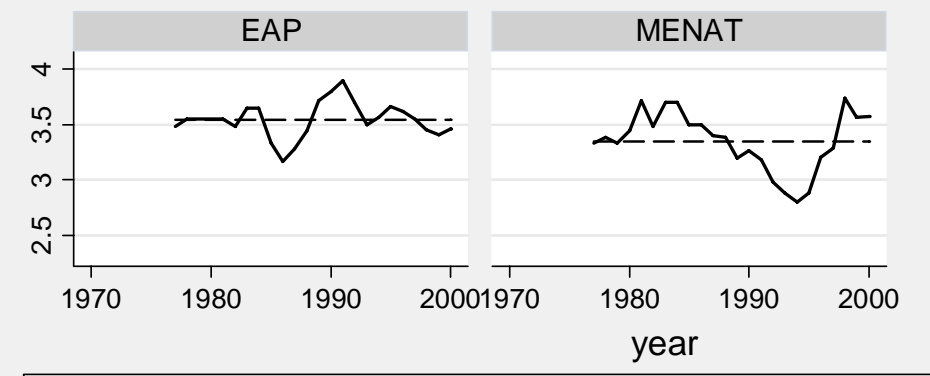

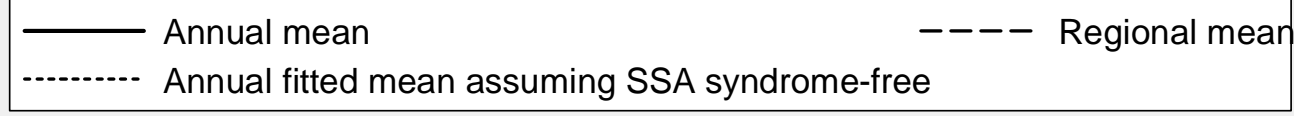
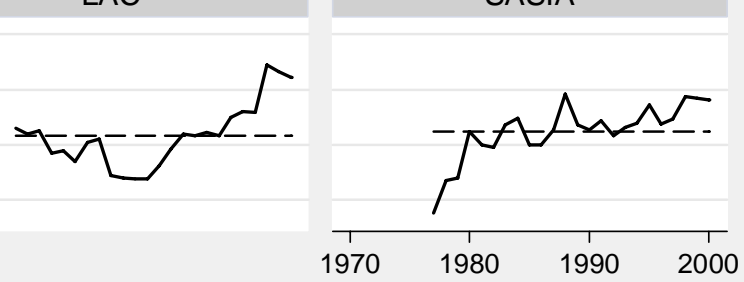

$1990-2000$

Note: ECA economies excluded to preserve scaling.

Table 14. Syndromes and the CPIA: annual panel regressions.

Dependent variable: CPIA score

\begin{tabular}{lll}
\hline Variable & OLS & FE \\
\hline Constant & $3.442^{\star \star \star}$ & $3.251^{\star \star \star}$ \\
& 0.078 & 0.081 \\
Soft & $-0.149^{\star \star \star}$ & $-0.333^{\star \star \star}$ \\
& 0.051 & 0.068 \\
Hard & $-0.556^{\star \star \star}$ & $-0.694^{\star \star *}$ \\
& 0.068 & 0.08 \\
Redistributive & $-0.595^{\star \star \star}$ & $-0.182^{\star \star \star}$ \\
& 0.055 & 0.070 \\
Intertemporal & $0.119^{\star}$ & 0.085 \\
& 0.066 & 0.074 \\
Breakdown & $-0.721^{\star \star \star}$ & $-0.419^{\star \star \star}$ \\
& 0.076 & 0.063 \\
\hline N & 1007 & 1007 \\
Adjusted $\mathrm{R}^{2}$ & 0.290 & 0.113 \\
RMSE & 0.688 & 0.513 \\
F & 17.948 & 7.213 \\
Prob>F & 0.000 & 0.000 \\
\hline All &
\end{tabular}

All regressions include year effects. The FE regression also includes country effects. The panel is unbalanced because we use all available observations. The omitted category is syndrome-free. 
Recall that our initial working assumption above has been that other regions did not experience policy and institutional dysfunction as severely as Africa: although countries elsewhere obviously made policy errors, the syndromes were unique to Africa. This working assumption is obviously inaccurate: other regions had countries with some deeply dysfunctional policies and institutions. We are now in a position to determine the extent to which our assumption is inaccurate. We begin in Table 15 which shows the average CPIA score for other regions, that for the years in Africa that were syndromefree, and that for those that were subject to one or other of the syndromes. The CPIA is a 1-5 scoring system, with low scores indicating worse policies and weaker institutions. In practice, the range of the scores is very largely confined to 2-4, with 2 indicating extremely bad circumstances, and 4 relatively good circumstances.

Table 15 suggests that our working assumption is not as inaccurate as might have been supposed. Taking the means of the CPIA scores, there is no significant difference between the entire non-African group and the group of African syndrome-free countryyears. By contrast, there is a large and significant difference between the African syndrome years on the one hand and both syndrome-free Africa and other regions, on the other. This is true both for the entire period for which we have data, 1977-2000, and for each sub-period individually, with the sole exception of 1985-92 when Africa's syndrome-free economies are rated above the economies of other regions, significant at $5 \%$. Strikingly, for our final period 1993-2000, the CPIA scores for syndrome-free Africa (3.30) and for other developing regions (3.34) are virtually identical. This does not imply that the syndromes were unique to Africa: obviously they were not. However, it does suggest that the greater prevalence and intensity in Africa of the policy problems that these syndromes describe may approximate to the extent to which Africa's policy environment was distinctive.

Table 15. Overall CPIA score by opportunity group, region and syndrome status.

\begin{tabular}{|c|c|c|c|c|c|c|c|}
\hline \multirow{2}{*}{$\begin{array}{l}\text { Region or } \\
\text { period }\end{array}$} & \multicolumn{3}{|c|}{ Sample statistics } & \multirow{2}{*}{\multicolumn{3}{|c|}{$\begin{array}{l}\text { Tests for difference in means } \\
\text { (row mean - column mean) }\end{array}$}} & \multirow{2}{*}{$\begin{array}{l}\text { Chi }^{2} \text { test } \\
\text { for differ- } \\
\text { ences in } \\
\text { variances } \\
\text { (p value) }\end{array}$} \\
\hline & Mean & Std Dev & Freq & & & & \\
\hline \multicolumn{8}{|c|}{$\begin{array}{l}\text { BY OPPORTUNITY GROUP } \\
\text { All non-industrial countries }\end{array}$} \\
\hline $\mathrm{CO}$ & 3.129 & 0.798 & 1449 & & $\mathrm{CO}$ & LL & \\
\hline LL & 2.860 & 0.769 & 479 & LL & $-0.270 * * *$ & -- & \\
\hline $\mathrm{RR}$ & 2.956 & 0.905 & 620 & $\mathrm{RR}$ & $-0.173 * * *$ & 0.096 & \\
\hline Total & 3.036 & 0.827 & 2548 & & & & 0.000 \\
\hline \multicolumn{8}{|l|}{ SSA only } \\
\hline $\mathrm{CO}$ & 2.860 & 0.744 & 439 & & $\mathrm{CO}$ & LL & \\
\hline LL & 2.701 & 0.791 & 309 & LL & $-0.159 * *$ & -- & \\
\hline $\mathrm{RR}$ & 2.731 & 0.921 & 282 & $\mathrm{RR}$ & -0.129 & 0.03 & \\
\hline Total & 2.777 & 0.812 & 1030 & & & & 0.000 \\
\hline
\end{tabular}

$<$ Table continued below $>$ 
Table 15 (continued).

\begin{tabular}{|c|c|c|c|c|c|c|c|}
\hline $\begin{array}{l}\text { Region or } \\
\text { period }\end{array}$ & \multicolumn{3}{|c|}{ Sample statistics } & \multicolumn{3}{|c|}{$\begin{array}{l}\text { Tests for difference in means (row } \\
\text { mean - column mean) }\end{array}$} & $\begin{array}{l}\text { Chi }^{2} \text { test } \\
\text { for differ- } \\
\text { ences in } \\
\text { variances } \\
\text { (p value) }\end{array}$ \\
\hline \multicolumn{7}{|c|}{$\begin{array}{l}\text { BY REGION AND SYNDROME STATUS } \\
\text { All vears } 1977-2000\end{array}$} & \\
\hline SSA sfr & 3.311 & 0.614 & 313 & \multirow{4}{*}{$\begin{array}{l}\text { SSA nfr } \\
\text { Other }\end{array}$} & \multirow{4}{*}{$\begin{array}{l}\text { SSA sfr } \\
-0.770 * * * \\
-0.099\end{array}$} & \multirow{4}{*}{$\begin{array}{l}\text { SSAnfr } \\
-- \\
0.670 * * *\end{array}$} & \\
\hline SSA nfr & 2.542 & 0.784 & 694 & & & & \\
\hline Other & 3.213 & 0.790 & 1518 & & & & \\
\hline Total & 3.041 & 0.828 & 2525 & & & & 0.000 \\
\hline \multicolumn{4}{|l|}{$1977-84$} & \multirow{5}{*}{$\begin{array}{l}\text { SSA nfr } \\
\text { Other }\end{array}$} & \multirow{5}{*}{$\begin{array}{l}\text { SSA sfr } \\
-0.647 * * * \\
-0.099\end{array}$} & \multirow{5}{*}{$\begin{array}{l}\text { SSAnfr } \\
-- \\
0.548 * * *\end{array}$} & \\
\hline SSA sfr & 3.363 & 0.615 & 43 & & & & \\
\hline SSA nfr & 2.715 & 0.729 & 260 & & & & \\
\hline Other & 3.264 & 0.833 & 424 & & & & \\
\hline Total & 3.073 & 0.829 & 727 & & & & 0.007 \\
\hline \multicolumn{4}{|l|}{$1985-92$} & \multirow{5}{*}{$\begin{array}{l}\text { SSA nfr } \\
\text { Other }\end{array}$} & \multirow{5}{*}{$\begin{array}{l}\text { SSA sfr } \\
-0.802 * * * \\
-0.309 * *\end{array}$} & \multirow{5}{*}{$\begin{array}{l}\text { SSAnfr } \\
-- \\
0.493 * * *\end{array}$} & \\
\hline SSA sfr & 3.318 & 0.813 & 77 & & & & \\
\hline SSA nfr & 2.516 & 0.843 & 262 & & & & \\
\hline Other & 3.009 & 0.881 & 492 & & & & \\
\hline Total & 2.882 & 0.902 & 831 & & & & 0.541 \\
\hline \multicolumn{4}{|l|}{$1993-2000$} & \multirow{5}{*}{$\begin{array}{l}\text { SSA nfr } \\
\text { Other }\end{array}$} & \multirow{5}{*}{$\begin{array}{l}\text { SSA sfr } \\
-0.977 * * * \\
0.046\end{array}$} & \multirow{5}{*}{$\begin{array}{l}\text { SSAnfr } \\
-- \\
1.023^{* * *}\end{array}$} & \\
\hline SSA sfr & 3.297 & 0.518 & 193 & & & & \\
\hline SSA nfr & 2.320 & 0.709 & 172 & & & & \\
\hline Other & 3.343 & 0.634 & 602 & & & & \\
\hline Total & 3.152 & 0.737 & 967 & & & & 0.000 \\
\hline
\end{tabular}

$* \mathrm{p}<.1 ; * * \mathrm{p}<.05 ; * * * \mathrm{p}<.01$.

Notes: SSA sfr and SSA nfr refer to syndrome-free and not-syndrome free. Other refers to all non-SSA observations. The test for differences in means is Bonferroni test. The test for differences in variances is Bartlett's test.

In Figures 4 and 5 we use the above results to infer the contribution, year-by-year of the syndromes to the difference between Africa's CPIA score and that for other developing regions. In Figure 4, the dotted line shows what the CPIA would have been for Africa in the absence of the syndromes, based on the regression of the first column of Table 14. Derived from this, Figure 5 shows the estimated shortfall in the CPIA for Africa, year-by-year attributable to the syndromes. 


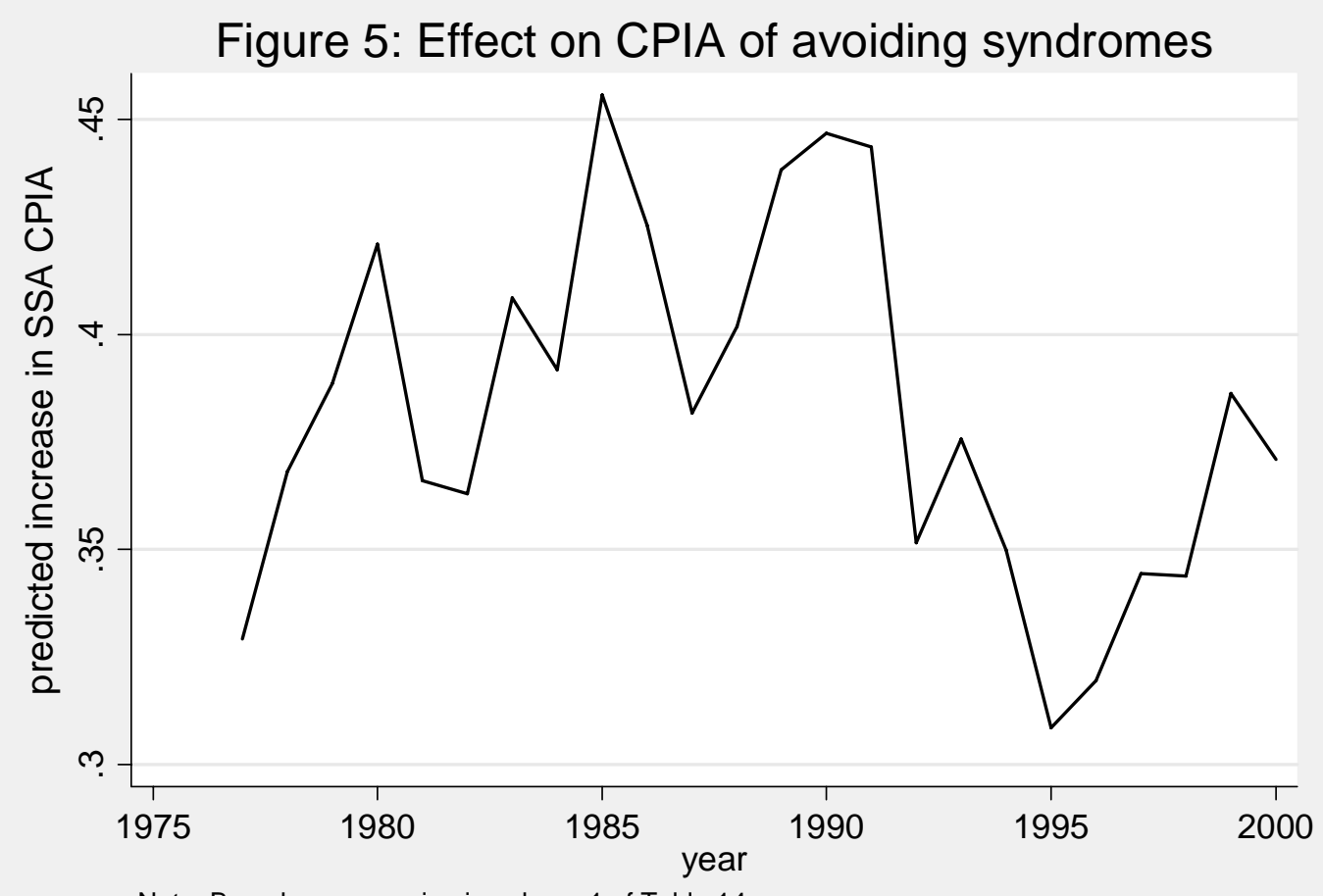

Note: Based on regression in column 1 of Table 14

Table 14 and Figure 5 are merely statements about averages. By definition, none of the African syndrome-free years were subject to syndromes, whereas undoubtedly some of the non-African countries experienced syndromes. This is indicated by the larger standard deviations for the non-African group. While Table 15 suggests that on average the difference between Africa and other low-income developing regions is equivalent to other regions not having experienced syndromes, evidently other regions did experience syndromes. We now infer how the incidence of syndromes evolved in Africa relative to other regions. We do this by using the observed relationship between the CPIA and syndromes in Africa to predict the incidence in other regions, through probit analysis. ${ }^{6}$ The results by decade are shown in Table 16.

Due to well known limitations of probit models, the overall incidence is of less interest than the trend. What is striking is that the predicted incidence of syndromes in other developing regions more than halves between the late 1970s and the 1990s. By contrast, the predicted incidence of syndromes in Africa falls much less sharply, by around a third. Other regions most surely suffered from syndromes, but they appear to have escaped from them much more rapidly.

\footnotetext{
${ }^{6}$ Estimation is for SSA country/years with cpia values 1977-2000. The estimated coefficient on cpia in a probit for syndrome-free status is 0.802 with standard error 0.071 (significant at the $1 \%$ level). This implies that a one-unit increase in cpia increases the probability of syndrome-free status by 24.9 percent. The probit equation includes a full set of year effects. The pseudo- $\mathrm{R}^{2}$ is 0.2081 and the $\mathrm{Wald}$ chi ${ }^{2}$ for overall fit is 182.27, with prob $>\mathrm{chi}^{2}$ of 0.000 .
} 
Table 16. Predicted incidence of syndromes over time, by region.

\begin{tabular}{|c|c|c|c|}
\hline $\begin{array}{l}\text { Period } \\
\text { and Region }\end{array}$ & \multicolumn{2}{|c|}{ Row proportion } & $\begin{array}{l}\text { Column } \\
\text { proportion }\end{array}$ \\
\hline $1977-2000$ & Not free & Free & Total \\
\hline Other & 55.27 & 44.73 & 57.22 \\
\hline SSA & 69.43 & 30.57 & 42.78 \\
\hline Total & 61.33 & 38.67 & 100 \\
\hline $1977-1979$ & Not free & Free & Total \\
\hline Other & 81.51 & 18.49 & 51.05 \\
\hline SSA & 85.00 & 15.00 & 48.95 \\
\hline Total & 83.22 & 16.78 & 100 \\
\hline 1980-89 & Not free & Free & Total \\
\hline Other & 82.65 & 17.35 & 55.32 \\
\hline SSA & 84.26 & 15.74 & 44.68 \\
\hline Total & 83.37 & 16.63 & 100 \\
\hline $1990-2000$ & Not free & Free & Total \\
\hline Other & 30.25 & 69.75 & 60.08 \\
\hline SSA & 52.00 & 48.00 & 39.92 \\
\hline Total & 38.94 & 61.06 & 100 \\
\hline
\end{tabular}

Notes: Predictions are from a probit regression of syndrome-free status on the cpia score, for all SSA country/years with available cpia values 1977-2000. The estimated coefficient on cpia is 1.025, with a standard error of 0.079 (significant at the 1\% level). This implies that a one-unit increase in cpia increases the probability of syndrome-free status by 31.5 percent. The probit equation includes a full set of year effects. The pseudo $\mathrm{R}^{2}$ is 0.3102 and the Wald chi ${ }^{2}$ for overall fit is 256.80 , with prob $>\mathrm{chi}^{2}$ of 0.000 .

\section{Syndromes and the Foreclosing of Opportunities}

We have suggested that different countries of Africa have faced different opportunities: that successful growth strategies during the period we analyze would inevitably have differed across the region. The coastal but resource-poor economies had the chance to follow the labor-intensive manufacturing route; the resource-rich economies needed to have effective public spending; while the landlocked resource-poor economies were dependent upon successful growth strategies in their neighbors. We now develop these hypotheses and subject them to some testing.

\section{Resource-Poor Coastal Economies}

We start with the coastal, resource-poor economies. Recall that this is indeed the biggest single factor in Africa's growth divergence with other regions. Further, the gap in performance between Africa and other regions in this opportunity category only really opens up from the 1980s and then rapidly becomes dramatically wide. This is at least consistent with the timing of Asia's breakthrough into labor-intensive manufactured and service exports. The first issue we investigate is whether the population-weighted divergence of Africa and other developing regions in this opportunity category is entirely driven by China and India. Of course, even if this is the case, the divergence is a real phenomenon. Nevertheless, it is important to establish whether the exceptional 
phenomenon is the take-off of these two populous countries relative to all other lowincome coastal resource-poor countries, or whether the exceptional phenomenon is the divergence of Africa. Table 17 compares the performance of African and other coastal resource-poor economies, with various exclusions from the non-Africa group. The key part is the fourth column of Table 17.2 which compares Africa with other economies that were low-income in the mid-1970s but which excludes China and India. The growth differential is indeed lower than when China and India are included, but it is still substantial, and it is still much higher post-1980 than pre-1980. Pre-1980 the differential is only around 1.3 percentage points, whereas post-1980 it is around 3.0 percentage points. There is thus some basis for concluding that Africa's coastal, resource-poor economies did indeed diverge massively from somewhat similar economies elsewhere after 1980.

Perhaps the most striking feature of economic development during our period is that, beginning in around 1980, developing countries have succeeded in breaking into the global market in manufactures, a change which became explosive. Between 1980 and 2000 the share of manufactures in developing countries exports rose from $25 \%$ to $80 \%$. Such explosive growth is consistent with the industrial agglomeration models of Krugman and Venables, with an initial agglomeration advantage for the rich countries being breached as the wage differential widened to a critical threshold. In these models, once industry begins to relocate, the initial agglomeration advantage declines and so growth in the 'South' - or at least in that part of it where industry initially chose to locate - explosively catches up the North. The role of the syndromes in closing off the opportunity to break into manufactured exports at the crucial time before Asia established economies of agglomeration is thus a contending explanation for why coastal Africa did not participate in this process. During the decade of the 1980s the coastal resource-scarce economies of Africa were virtually all in the grip of one or other of the syndromes. Going through the countries in the coastal, resource-poor category, Cote d'Ivoire and Senegal were handicapped by the combination of minimum wage laws and the Franc Zone, which prevented them inflating away from uncompetitive real wages. Mozambique, Ethiopia, and Sierra Leone were war-torn. Sudan, as well as being periodically war torn, is, as Sachs would argue, scarcely a coastal economy, since the overwhelming bulk of its population and its cities are landlocked. South Africa was entering a period of anticipated redistribution and consequent high uncertainty. The remaining economies in the category were Ghana, Kenya, Guinea, Mauritius and Tanzania. Of these, Ghana emerged from syndromes during the late 1980s and it is an important question to what extent by the end of our period it had succeeded in diversifying its exports. Tanzania emerged from syndromes a little later than Ghana and so the same question applies. Kenya was in the grip of regional redistribution for the entire post-1980 period. Only Mauritius was syndrome free for the entire post-1980 period. It did indeed succeed in breaking into manufactured and service exports and become a middle-income economy.

Table 17. Coastal, resource-poor economies compared.

\begin{tabular}{|l|l|l}
\hline \multirow{2}{*}{ Decade } & Developing countries & Low-income developing countries ${ }^{*}$ \\
& &
\end{tabular}




\begin{tabular}{|c|c|c|c|c|c|c|c|c|}
\hline & \multicolumn{2}{|c|}{ All } & \multicolumn{2}{|c|}{$\begin{array}{l}\text { Excluding China } \\
\text { and India }\end{array}$} & \multicolumn{2}{|c|}{ All } & \multicolumn{2}{|c|}{$\begin{array}{l}\text { Excluding China } \\
\text { and India }\end{array}$} \\
\hline \multicolumn{3}{|c|}{ Number of countries } & & & & & & \\
\hline & Other & SSA & Other & SSA & Other & SSA & Other & SSA \\
\hline 1960s & 46.7 & 24 & 44.7 & 24 & 11 & 17 & 9 & 17 \\
\hline 1970s & 41 & 21.1 & 39 & 21.1 & 10 & 14.8 & 8 & 14.8 \\
\hline 1980s & 39 & 17.9 & 37 & 17.9 & 10 & 12.9 & 8 & 12.9 \\
\hline $1990-2000$ & 39 & 16.9 & 37 & 16.9 & 10 & 12.4 & 8 & 12.4 \\
\hline Total & 41.2 & 19.8 & 39.2 & 19.8 & 10.2 & 14.1 & 8.2 & 14.1 \\
\hline \multicolumn{9}{|c|}{ Population-weighted growth differential (Other minus SSA) } \\
\hline $1960 \mathrm{~s}$ & \multicolumn{2}{|c|}{0.89} & \multicolumn{2}{|c|}{1.34} & \multicolumn{2}{|c|}{1.05} & \multicolumn{2}{|c|}{1.22} \\
\hline 1970s & \multicolumn{2}{|c|}{1.86} & \multicolumn{2}{|c|}{1.87} & \multicolumn{2}{|c|}{1.72} & \multicolumn{2}{|c|}{0.52} \\
\hline 1980s & \multicolumn{2}{|c|}{5.53} & \multicolumn{2}{|c|}{2.61} & \multicolumn{2}{|c|}{6.39} & \multicolumn{2}{|c|}{3.89} \\
\hline $1990-2000$ & \multicolumn{2}{|c|}{4.46} & \multicolumn{2}{|c|}{1.75} & \multicolumn{2}{|c|}{4.98} & \multicolumn{2}{|c|}{1.96} \\
\hline Total & \multicolumn{2}{|c|}{3.28} & \multicolumn{2}{|c|}{1.90} & \multicolumn{2}{|c|}{3.63} & \multicolumn{2}{|c|}{1.92} \\
\hline
\end{tabular}

Notes: ${ }^{*}$ Low-income economies are those whose average PPP-adjusted real GDP per capita between 1973 and 1977 was below $\$ 2450$ at 1996 international prices.

We next investigate whether there is a statistical relationship between the extent to which Africa's resource-scarce coastal economies expanded their manufactured and service exports and the extent to which they avoided the syndromes. Specifically, we consider whether the number of years that an economy was free from syndromes post1979 is significant in explaining the trend in the share on manufactured and service exports in GDP. When we aggregate all the syndromes many of the countries are concentrated around zero years syndrome-free. To remedy this loss of variation we also consider only the regulatory syndrome which is both the most common one for the coastal economies and also probably the most destructive for export opportunities. We consider manufacturing and service exports both separately and together. Figure 6 graphs the relationship and Table 18 reports the regression results. The persistence of the regulatory syndrome in the resource-scarce coastal economies is indeed significant in reducing the growth of manufacturing exports, service exports, and their combination. Despite the lack of variation, the persistence of the totality of syndromes is also significant except for manufactured exports. Not only are the results statistically significant, they are large. Because our dependent variable is the trend in exports, an implication is that the effect of removing the syndromes is gradual and cumulative. By the end of two decades, the difference between a country such as Mauritius, which was free of the syndrome for the entire period, and a country such as Togo which maintained the syndrome for 21 of the 24 years covered in Table 18, is predicted to be 20 years $*(21 \cdot 0.068)=28.5$ percent of GDP (for manufacturing + service exports). However, an out-of-sample extrapolation would imply that this is a widening difference: Mauritius is on an export growth path, whereas Togo is not. 
Table 18. African coastal economies: syndrome status and export diversification, 1980-2000.

\begin{tabular}{|c|c|c|c|c|c|c|}
\hline \multirow{2}{*}{ Variable } & \multicolumn{6}{|c|}{$\begin{array}{l}\text { Dependent variable: estimated linear trend, 1980-2000, } \\
\text { in: }\end{array}$} \\
\hline & \multicolumn{2}{|c|}{$\begin{array}{l}\text { Manufactured } \\
\text { exports/GDP }\end{array}$} & \multicolumn{2}{|c|}{$\begin{array}{l}\text { Commercial Service } \\
\text { exports/GDP }\end{array}$} & \multicolumn{2}{|c|}{$\begin{array}{l}\text { Non-primary } \\
\text { exports/GDP }\end{array}$} \\
\hline Constant & $0.147^{*}$ & 0.025 & -0.091 & -0.275 & -0.067 & -0.312 \\
\hline & 0.069 & 0.068 & 0.215 & 0.193 & 0.33 & 0.299 \\
\hline Years syndrome-free & 0.012 & -- & $0.034 *$ & -- & $0.078^{*}$ & -- \\
\hline & 0.007 & & 0.016 & & 0.04 & \\
\hline Years control-free & -- & $\begin{array}{l}0.015^{* * * *} \\
0.005\end{array}$ & -- & $\begin{array}{l}0.048^{* *} \\
0.016\end{array}$ & -- & $\begin{array}{l}0.091^{* *} \\
0.037\end{array}$ \\
\hline $\mathrm{N}$ & 15 & 15 & 13 & 13 & 13 & 13 \\
\hline Adjusted $\mathrm{R}^{2}$ & 0.046 & 0.236 & 0.237 & 0.508 & 0.276 & 0.379 \\
\hline RMSE & 0.216 & 0.193 & 0.396 & 0.318 & 0.814 & 0.754 \\
\hline $\mathrm{F}$ & 1.666 & 6.822 & 4.831 & 8.114 & 3.429 & 5.96 \\
\hline
\end{tabular}

${ }^{*} \mathrm{p}<.1 ; * * \mathrm{p}<.05 ;{ }^{* * *} \mathrm{p}<.01$. Estimation is by OLS. Robust standard errors are below the coefficient estimates.

Figure 6: Syndromes and Export Diversification Coastal SSA, 1979-2000
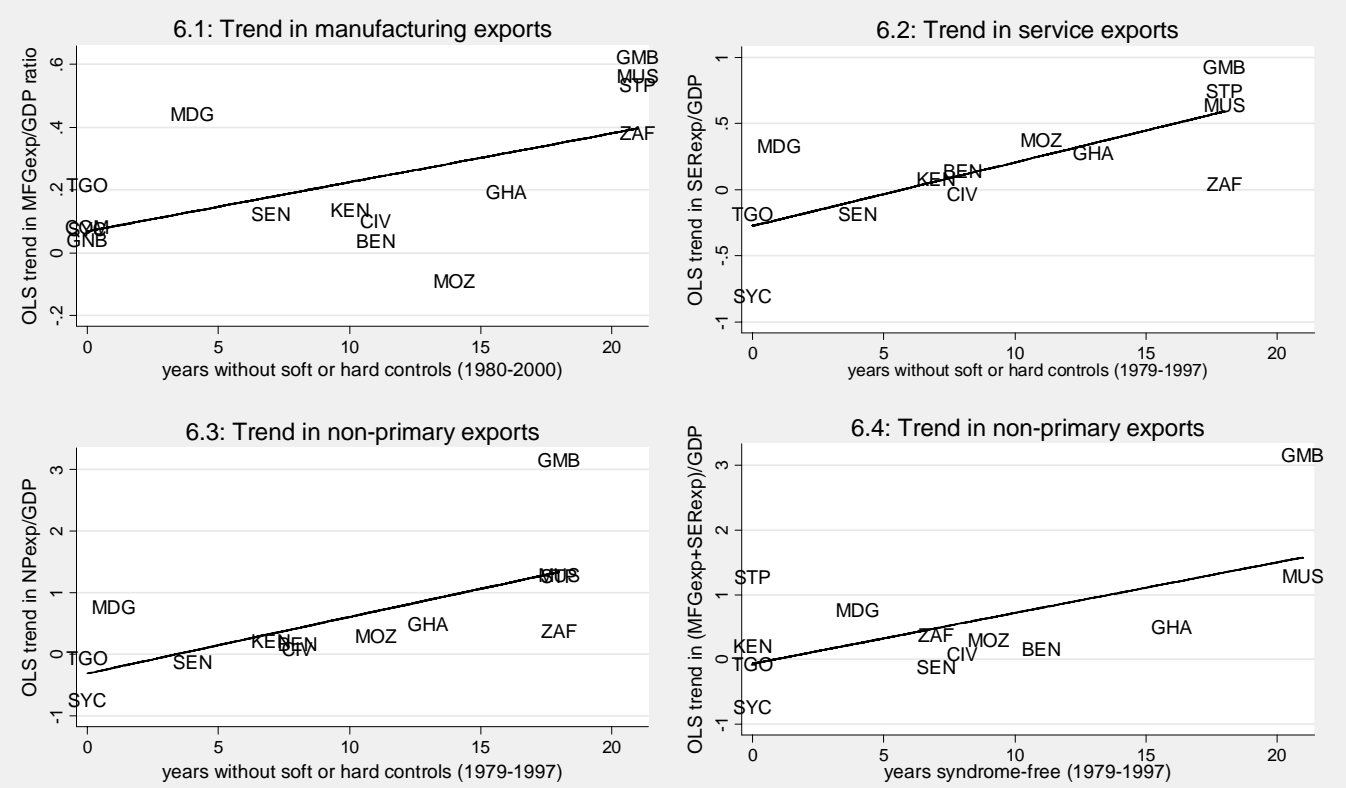

Note: See Table 18. 


\section{Resource-Rich Economies}

Turning to the second of our questions, recall that in the 1960s there were virtually no resource-rich economies in Africa. However, post-1970, when such economies started to become more common, only a small minority have been syndrome-free. Indeed, even during the 1990s of the $30 \%$ of Africa's population living in resource-rich economies, all but $4 \%$ were living with one or other of the syndromes. The most frequent syndromes in the resource-rich economies were redistributive and inter-temporal. Indeed, the two syndromes often co-existed: for example, the government would borrow internationally in order to magnify its transfers to its favored group.

Although almost all of Africa's resource-rich economies failed to harness their potential for growth, Botswana stands out as an extraordinary exception analogous to Mauritius among the coastal economies. Botswana maintained standards of governance that enabled it to use its resource wealth to attain middle-income status, growing exceptionally fast even by global standards. Evidently, globally resource wealth posed problems for governance, but with the exception of Botswana the other African resourcerich countries did significantly worse than the global average. Why might this have happened?

Resource wealth poses in its starkest form the choice between public goods and transfers. A result already well-established in the literature is that when small, clearlydefined groups hold power they have an incentive to prioritize transfers over the public good of growth (Adam and O'Connell, 1992). Ethnicity is obviously the most potent such social cleavage. Hence theory would predict that ethnic diversity makes autocracy particularly damaging: the power base for the autocracy being a single ethnic group, there is a strong incentive for redistribution over growth. This prediction is consistent with the global econometric evidence. Although there is usually no clear relationship between democracy and growth, once ethnic diversity is introduced as an interaction with democracy, there is a clear and substantial effect: democracy promotes growth in the context of ethnic diversity (Collier, 2000; Alesina and La Ferrara, 2004). Further, globally, resource rents significantly increase the probability of autocracy (Collier and Hoeffler, 2005).

African societies are distinctively different from those of other regions in two respects that are pertinent for these global relationships. First, as is well-known, they are characterized by atypically high ethnic diversity. Secondly, during our period, they have been atypically prone to autocracy. The implication of these characteristics and the above global relationships is that we would indeed expect Africa's resource-rich economies to have differentially worse performance than other regions. On this explanation, Africa's resource-rich countries underperformed those of other regions because they were more likely to be characterized by the toxic combination of ethnic diversity and autocracy. This is borne out in Table 19 which measures the political regime and ethnic diversity by opportunity group and decade both for Africa and for other regions. We present the results both unweighted and with population weights: the former are more pertinent as a description of the typical country, and the latter for growth outcomes. Our key interest is the conjunction of high ethnic diversity with low democracy. Using standard scoring systems we first consider the average of this ratio over the entire forty years. The result is striking: among the six categories generated by the three opportunity groups and the 
distinction between Africa and other regions, Africa's resource-rich countries come top. On the unweighted data the different is dramatic: for Africa's resource-rich countries the ratio is more than double that of other regions, though for the weighted data the difference is narrower. Turning to the decade-by-decade data, we see that the 1960s are anomalous. During 1970-2000 Africa's resource-rich countries were consistently far more characterized by the cocktail of high ethnic diversity and low democracy than both the other African opportunity groups and the resource-rich countries of other regions. Finally, looking to the underlying ethnic diversity and democracy scores, we see that this was generally driven both by higher diversity and by lower democracy. By the 1990s, although globally the resource-rich countries were lagging behind in terms of democratization, outside Africa such countries were substantially more democratic than their African counterparts.

As we argue in the chapter on inter-temporal syndromes, there may be a further catch: democracy is prone to malfunction in the context of resource wealth. Empirically, the global relationship between resource wealth, democracy and growth is adverse: when resource rents are substantial democracy significantly reduces growth (Collier and Hoeffler, 2005). One explanation for this result is that resource rents tend to subvert democracy by providing the finance that makes patronage politics the dominating electoral strategy. Collier and Hoeffler show that empirically the problem of democracy in the context of resource rents comes only from electoral competition; checks and balances, the other feature of democracy, are differentially beneficial to growth in the context of resource rents. Presumably, sufficient checks and balances make patronage politics infeasible even in the context of resource wealth. Hence, it is not democracy per se, but rather the type of democracy that matters: resource-rich societies need a form of democracy characterized by checks and balances rather than by intense electoral competition. This happens to describe Botswana. Electoral competition is rather limited: despite continuous democracy there has never been a change of government. Yet, perhaps because democracy has been continuous, the non-electoral checks and balances that work through due process have never been undermined. Nigeria under Shagari, although also a democracy, was clearly at the other end of the spectrum: a brief period of electoral competition in a context in which due process had already collapsed under previous military regimes. The Shagari regime presided over the single most important missed opportunity for growth that resource-rich Africa has had during our period.

\section{Resource-Scarce Landlocked Economies}

Finally, we turn to the landlocked, resource-poor economies. Our hypothesis here is that globally the performance of such economies should be dependent upon whether more fortunately endowed neighbors are growing. This is because the most obvious growth strategy for such a country is to service the markets of its neighbors. In Table 20 we test this hypothesis both for other regions and for Africa in a growth regression. To check robustness we use three approaches, OLS, IV, and LAD (the LAD regressions are in appendix Table A3). Globally, the growth of neighbors matters, which is unsurprising. Further, globally the landlocked, resource-poor economies indeed are more dependent than other economies on the growth of their neighbors: from the OLS results, whereas the typical growth spillover of an additional one percentage point on the growth rate of 
neighbors is 0.4 percentage points, for the landlocked, resource-poor it is 0.7 percentage points. However, all African economies depart from this global pattern: neighborhood growth spillovers are much weaker, and indeed for Africa's landlocked, resource-poor countries there are no significant neighborhood growth spillovers.

Table 19. Democracy and ethnic fractionalization by opportunity category and decade.

\begin{tabular}{|c|c|c|c|c|c|c|c|}
\hline \multirow{2}{*}{\multicolumn{2}{|c|}{$\begin{array}{l}\text { Variable, region } \\
\text { and decade }\end{array}$}} & \multicolumn{3}{|c|}{ Unweighted } & \multicolumn{3}{|c|}{ Population-weighted } \\
\hline & & $\mathrm{CO}$ & LL & $\mathrm{RR}$ & $\mathrm{CO}$ & LL & $\mathrm{RR}$ \\
\hline \multicolumn{8}{|c|}{ Polity 4 democracy score } \\
\hline \multirow[t]{5}{*}{ SSA } & $1960 \mathrm{~s}$ & 2.11 & 1.35 & 1.57 & 2.84 & 1.77 & 2.55 \\
\hline & 1970s & 1.53 & 0.68 & 0.98 & 1.39 & 0.77 & 0.91 \\
\hline & 1980s & 1.47 & 0.60 & 0.88 & 1.44 & 1.22 & 2.35 \\
\hline & $1990-2000$ & 3.23 & 1.97 & 2.16 & 3.44 & 1.65 & 1.10 \\
\hline & Total & 2.07 & 1.15 & 1.41 & 2.26 & 1.36 & 1.54 \\
\hline \multirow[t]{5}{*}{ Other } & 1960s & 3.22 & 0.10 & 2.50 & 3.36 & 0.08 & 1.16 \\
\hline & 1970s & 2.88 & 0.00 & 1.99 & 3.18 & 0.00 & 0.72 \\
\hline & 1980s & 3.68 & 0.42 & 2.76 & 3.37 & 1.36 & 1.13 \\
\hline & $1990-2000$ & 5.71 & 4.02 & 3.69 & 4.43 & 5.64 & 2.24 \\
\hline & Total & 3.89 & 1.20 & 2.85 & 3.60 & 1.76 & 1.38 \\
\hline \multicolumn{8}{|c|}{ Ethnic fractionalization index } \\
\hline \multirow[t]{5}{*}{ SSA } & $1960 \mathrm{~s}$ & 68.06 & 57.00 & 68.80 & 77.43 & 64.69 & 74.57 \\
\hline & 1970s & 67.12 & 57.45 & 68.40 & 73.73 & 64.85 & 84.06 \\
\hline & 1980s & 64.62 & 57.50 & 71.20 & 72.31 & 64.85 & 84.38 \\
\hline & $1990-2000$ & 64.39 & 58.08 & 71.20 & 72.96 & 65.81 & 84.38 \\
\hline & Total & 66.21 & 57.52 & 70.20 & 74.54 & 65.12 & 83.88 \\
\hline \multirow[t]{5}{*}{ Other } & 1960s & 32.64 & 50.67 & 37.29 & 62.18 & 61.49 & 46.17 \\
\hline & 1970s & 31.74 & 46.33 & 40.59 & 61.40 & 59.57 & 59.89 \\
\hline & 1980s & 29.58 & 42.00 & 45.15 & 61.55 & 59.57 & 59.31 \\
\hline & $1990-2000$ & 29.58 & 42.00 & 45.15 & 61.55 & 59.57 & 59.31 \\
\hline & Total & 30.93 & 45.79 & 42.85 & 61.68 & 60.14 & 58.09 \\
\hline \multicolumn{8}{|c|}{ Ratio: Ethnic fractionalization/ $(1+$ democracy score $)$} \\
\hline \multirow[t]{5}{*}{ SSA } & $1960 \mathrm{~s}$ & 50.67 & 51.44 & 46.54 & 49.29 & 51.54 & 35.15 \\
\hline & 1970s & 51.78 & 51.48 & 59.48 & 58.91 & 58.77 & 74.70 \\
\hline & $1980 s$ & 45.56 & 49.00 & 63.62 & 55.83 & 50.43 & 61.78 \\
\hline & $1990-2000$ & 33.83 & 40.81 & 43.75 & 38.62 & 46.04 & 64.55 \\
\hline & Total & 46.20 & 47.83 & 54.19 & 51.37 & 51.13 & 65.22 \\
\hline \multirow[t]{5}{*}{ Other } & 1960s & 16.12 & 46.13 & 23.93 & 18.81 & 58.40 & 44.45 \\
\hline & 1970s & 17.92 & 46.33 & 28.72 & 14.70 & 59.57 & 57.33 \\
\hline & 1980 s & 13.92 & 20.48 & 27.44 & 13.88 & 25.20 & 52.82 \\
\hline & $1990-2000$ & 7.04 & 6.61 & 19.72 & 8.39 & 9.45 & 43.07 \\
\hline & Total & 13.68 & 31.78 & 24.74 & 13.95 & 38.86 & 50.01 \\
\hline
\end{tabular}

Notes: The table uses all countries with at least 30 years of data on the democracy index between 1960 and 2000. ${ }^{*}$ The fractionalization index applies to the early 1960s and is time-invariant. Averages change over time as the country composition varies by opportunity category. 
Table 20. Neighbor effects on growth.

Dependent variable: growth of real GDP per capita.

\begin{tabular}{|c|c|c|c|c|c|c|}
\hline \multirow{2}{*}{ Variable } & \multicolumn{3}{|c|}{ OLS regressions } & \multicolumn{3}{|c|}{ IV regressions ${ }^{*}$} \\
\hline & (1) & $(2)$ & (3) & (4) & (5) & (6) \\
\hline \multirow[t]{2}{*}{ Landlocked (LL) } & $-1.003 * * *$ & $-1.003^{* * *}$ & $-1.633 * * *$ & $-1.118^{* * *}$ & $-1.136 * * *$ & $-1.942^{* *}$ \\
\hline & 0.291 & 0.291 & 0.526 & 0.298 & 0.299 & 0.794 \\
\hline \multirow[t]{2}{*}{ Resource-rich (RR) } & $-0.819 * * *$ & $-0.821 * * *$ & $-0.746^{* *}$ & $-0.649 * *$ & $-0.643 * *$ & -0.533 \\
\hline & 0.306 & 0.306 & 0.341 & 0.318 & 0.319 & 0.423 \\
\hline \multirow[t]{2}{*}{ Island } & $1.852 * * *$ & $1.852 * * *$ & $1.777 * * *$ & $2.378 * * *$ & $2.413^{* * *}$ & $2.252 * * *$ \\
\hline & 0.253 & 0.253 & 0.267 & 0.309 & 0.311 & 0.341 \\
\hline \multirow[t]{2}{*}{ Neighbor growth } & $0.428 * * *$ & $0.428 * * *$ & $0.392 * * *$ & $0.719 * * *$ & $0.742 * * *$ & $0.659 * * *$ \\
\hline & 0.046 & 0.046 & 0.06 & 0.11 & 0.113 & 0.14 \\
\hline \multirow[t]{2}{*}{$\mathrm{CO}^{*} \mathrm{SSA}$} & $-0.967 * * *$ & $-0.957 * * *$ & $-1.027 * * *$ & -0.382 & -0.4 & -0.549 \\
\hline & 0.299 & 0.304 & 0.319 & 0.362 & 0.425 & 0.453 \\
\hline \multirow[t]{2}{*}{$\mathrm{LL} * \mathrm{SSA}$} & 0.002 & -0.017 & 0.546 & 0.68 & 0.727 & $1.381^{*}$ \\
\hline & 0.426 & 0.427 & 0.571 & 0.505 & 0.514 & 0.822 \\
\hline \multirow[t]{2}{*}{$\mathrm{RR} * \mathrm{SSA}$} & 0.361 & 0.317 & 0.178 & 0.69 & 0.985 & 0.728 \\
\hline & 0.57 & 0.57 & 0.573 & 0.597 & 0.645 & 0.654 \\
\hline \multirow[t]{2}{*}{ Island*SSA } & -0.765 & -0.774 & -0.699 & $-1.394^{* *}$ & $-1.373 *$ & $-1.218^{*}$ \\
\hline & 0.638 & 0.641 & 0.646 & 0.664 & 0.703 & 0.714 \\
\hline \multirow[t]{2}{*}{ Neighbor growth*LL } & -- & -- & $0.318^{* *}$ & -- & -- & 0.418 \\
\hline & -- & -- & 0.157 & -- & -- & 0.309 \\
\hline \multirow[t]{2}{*}{ Neighbor growth*RR } & -- & -- & -0.083 & -- & -- & -0.135 \\
\hline & -- & -- & 0.09 & -- & -- & 0.211 \\
\hline \multirow[t]{2}{*}{ Nbr growth*CO*SSA } & -- & $-0.313^{* * *}$ & $-0.278 * * *$ & -- & $-0.529 *$ & -0.463 \\
\hline & -- & 0.085 & 0.093 & -- & 0.312 & 0.317 \\
\hline \multirow[t]{2}{*}{ Nbr growth*LL*SSA } & -- & $-0.181^{* *}$ & $-0.462 * * *$ & -- & -0.579 & $-0.925^{*}$ \\
\hline & -- & 0.091 & 0.165 & -- & 0.434 & 0.51 \\
\hline \multirow[t]{2}{*}{ Nbr growth*RR*SSA } & -- & $-0.391 * * *$ & $-0.270 * *$ & -- & -0.097 & 0.117 \\
\hline & -- & 0.128 & 0.137 & -- & 0.282 & 0.313 \\
\hline \multirow[t]{2}{*}{ Nbr growth*SSA } & $-0.304 * * *$ & -- & -- & $-0.584 * * *$ & -- & -- \\
\hline & 0.072 & -- & -- & 0.119 & -- & -- \\
\hline \multirow[t]{2}{*}{ Dry year } & -0.302 & -0.304 & -0.322 & -0.305 & -0.236 & -0.268 \\
\hline & 0.212 & 0.212 & 0.211 & 0.216 & 0.233 & 0.233 \\
\hline $\mathrm{N}$ & 5620 & 5620 & 5620 & 5399 & 5399 & 5399 \\
\hline R2_a & 0.097 & 0.098 & 0.101 & 0.084 & 0.07 & 0.078 \\
\hline Rmse & 6.263 & 6.262 & 6.249 & 6.338 & 6.389 & 6.361 \\
\hline $\mathrm{F}$ & 9.800 & 9.494 & 9.234 & 9.22 & 8.849 & 8.731 \\
\hline
\end{tabular}

legend: * $\mathrm{p}<.1 ; * * \mathrm{p}<.05 ; * * * \mathrm{p}<.01$. All regressions include a full set of year effects. ${ }^{*}$ Instruments for variables involving neighbor growth are the first and second lags of all such variables.

The most likely explanation for this striking result is that Africa's internal barriers to trade are much higher than other regions. This is consistent with evidence on both the actual practice of trade policies and the very high level of transport costs. The differential lack of a growth spillover effect for Africa's landlocked economies, contrasted with the differentially large effect for such economies elsewhere, suggests that such barriers may be atypically high even by African standards. This is plausible: being landlocked not only raises costs of transport to global markets but also raises them to other African markets. 
Paradoxically, to date this isolation of Africa's landlocked, resource-poor economies from their neighborhoods has not mattered very much for their growth. Although as a group these countries have grown more slowly than their more fortunately endowed neighbors, the gap has been much narrower than that in other regions. The lack of integration of Africa's landlocked economies matters more for the future when its more fortunate countries indeed succeed in harnessing their opportunities. Then, in an ideal world, the landlocked, resource-poor would be carried along by the growth of their neighbors, as in other regions. In Africa, on past levels of integration, even when the countries with better opportunities succeed in harnessing them, there is going to be no such spillover effect. The most credible growth prospect for the poorest countries of Africa is currently closed off by the region's internal barriers.

\section{A Preliminary Conclusion}

Misunderstanding the past makes it harder to change the future. What have we learnt from this chapter that might be helpful for the shaping of African development strategies?

\section{Understanding the past}

Changing Africa's future from the trends of 1960-2000 is evidently of global concern: the region was stagnant during a period of unprecedented global growth. It is currently fashionable to come up with single explanations for this massive failure of the growth process: the region is irretrievably aid-dependent (Lal, 1999); it has uniquely unfavorable geography (Gallup and Sachs, 1997; Sachs et al, 2005); it has inherited dysfunctional institutions (Acemoglu, Johnson and Robinson, 2001). We have argued that such explanations ignore important variation: geographic opportunities differed across Africa, and choices also differed. While introducing variation we have been parsimonious: Africa's 48 countries and 40 years of behavior-1920 observations-have been collapsed into three opportunity groups and a choice between being syndrome-free and four syndromes.

Our foremost objective has, of course, been to provide an account of the past failure of the growth process. The annual growth shortfall to be explained is 3.5 percentage points.

Of this, we attribute around one percentage point to Africa's inherently inferior growth opportunities: its population is heavily skewed away from the fast-growth opportunity of being resource-scarce and coastal. We attribute nearly two percentage points to the damage done by one or other of the four policy syndromes: regulatory, inter-temporal, redistributive, and state breakdown. The shortfall in Africa's policies and institutions relative to other regions was closely equivalent to the effect of these syndromes.

Our account of the failure of the growth process is thus in essence as follows. Globally, there have been two autonomous paths to middle-income status. Resource-rich economies can succeed, but since such economies will necessarily have a large state, the critical governance issue is how the state spends money. Coast, resource-scarce economies can also succeed, but since their success depends upon keeping costs at globally competitive levels, the critical governance issue is that the state should not be predatory upon the export sector. The landlocked resource-scarce economies lack an 
autonomous path to middle-income status, unless their more fortunate neighbors harness their growth opportunities. Conditional upon this, such economies succeed by integrating within their region, servicing their fast-growing neighbors.

In Africa, the relative balance of autonomous growth opportunities was distinctive because the two paths were equally important whereas globally the labor-intensive exports path was far more important. Africa's socio-political structure was unusually illsuited to this importance of resource wealth. Globally, the cocktail of resource-wealth, ethnic diversity and autocracy has usually been toxic for growth. This manifested itself as a high incidence of the redistributive and inter-temporal syndromes in these economies. The resource-scarce coastal economies were disproportionately prone to the regulatory syndrome. During the critical decade of the 1980s, when these countries could potentially have matched Asia in breaking in to new global markets, only Mauritius was syndromefree. Since the 1980s it has become much harder to follow this growth path because of the agglomeration economies now built up by China and India. Nevertheless, those African coastal economies that have escaped from syndromes have started to succeed in new export markets. Africa's resource-scarce landlocked economies have faced a triplebind. Their more fortunate neighbors had usually foreclosed their growth opportunities through one or other of the syndromes. Over-and-above this, the land countries faced transport and policy barriers to regional integration that made it difficult to latch onto neighboring success in the rare cases where it occurred. Perhaps the prevailing stagnation reduced the political incentive for integration. Finally, the landlocked economies were disproportionately prone to the syndromes. Again, this might have been because, lacking a viable growth strategy, there was less incentive to avoid them.

Because of the radically greater importance of countries with resource wealth and countries that lacked such wealth and were landlocked, Africa's needed priorities were distinctive. The region needed to make the 'big state' work effectively, and it needed regional integration. Whether external policy pressure has had much effect is beyond our scope, but we note that these two issues have not been its priorities. External priorities towards the state have been to reduce its size, and towards trade they have been external liberalization. These priorities were probably appropriate predominantly for the minority of economies that were coastal, resource-scarce.

\section{Facing the Future}

We close by speculating about Africa's future growth. Clearly, on our thesis the syndromes have been the proximate impediments to African growth. Hence, the first priority is to avoid them. This may be extremely difficult because some of them may develop a trap-like persistence. Options for avoidance are discussed in the chapters devoted to each specific syndrome. Here our main concern is the implications of an environment beyond the syndromes. The key issue is whether, by avoiding the syndromes, Africa can replicate the success of other regions. Again we start from the two autonomous growth strategies.

Were the resource-rich countries to avoid the syndromes there seems no reason why they could not grow. Botswana is the practical demonstration of this possibility. However, it may be extremely difficult for the rest of resource-rich Africa to follow this path. We have argued that in the African context autocracies are likely to handle resource 
wealth very badly, but that democracies face equivalent problems from patronage politics unless they are able to construct effective checks and balances though due process. Such checks and balances are not an automatic concomitant of electoral competition, and democratic patronage politics has no incentive to construct them. Worse, the corruption that is at the center of the problems of these societies may be highly persistent (Tirole, 1996). Thus, the legacy of the syndromes might be trap of corruption.

Were the resource-scarce coastal economies now to escape the syndromes it is much more of an open question whether they would match the growth of other regions. During the 1990s even those economies that avoided the syndromes grew markedly less rapidly than other regions. There are three broad explanations for this shortfall. One is simply that there are inevitable lags between reform and private investment. On our evidence, after a decade of being syndrome-free such economies can expect to be raising their share of manufactured and service exports in GDP at around 0.2 percentage points a year, and after two decades at around 0.4 percentage points a year: success is accelerating. A second explanation is more disturbing: coastal Africa has missed the boat. Whereas in the 1980s Africa could have broken into global markets, now that Asia is established, Africa has no comparative advantage in labor costs to offset its disadvantage in the lack of agglomeration. If this is right, coastal Africa must look elsewhere for growth, perhaps by emulating Latin America in adding value to its resource-based exports. On the third explanation the avoidance of syndromes is necessary but insufficient for success in new exports. Success requires some positive actions by the state, such as the provision of infrastructure or education. In our view there is currently insufficient evidence decisively to reject any of these three explanations with radically different implications.

On the basis of our analysis of the past, The resource-scarce landlocked economies have little prospect of a growth path to middle-income status until their more fortunate neighbors succeed. Even then, they are dependent upon infrastructure and trade policies that integrate their economies with their neighbors, and this evidently requires the cooperation of their neighbors. This may be overly pessimistic. The growth opportunities for resource-scarce landlocked economies may be transformed through two new opportunities. First, there is a whole new class of service exports that are not significantly handicapped by being landlocked. Secondly, many landlocked countries have untapped natural resource wealth and can transform themselves into resource-rich economies.

Thus, while the analysis of the past offers some guidance, it leaves major uncertainties. A safety-first strategy would evidently allow for these uncertainties. Given the uncertainty attaching to autonomous processes of governance reform in the resourcerich countries, and the importance of such reform for the resource-scarce landlocked economies, the latter have good reason to attempt to reinforce internal processes of reform with neighborhood pressure through the African Union. Given the uncertainty attaching to the prospect of coastal economies breaking into export markets, governments would be wise to adopt a maximal strategy: taking positive actions beyond avoiding the syndromes. Given the uncertainty of other options, the resource-scarce landlocked economies would be wise to encourage resource prospecting, and to invest in the facilities necessary for the new service exports. 
Achieving growth in Africa is thus unlikely to be an easy matter for its societies. For different reasons, Botswana and Mauritius are deceptive models for growth. Africa's resource-rich economies will find it extremely difficult to construct the checks and balances that have enabled Botswana to grow. Africa's coastal economies will find the global market much more difficult to penetrate than did Mauritius which broke in before low-income Asia was established and additionally benefited from substantial protection from Asian competition. The third of Africa's population that is in resource-scarce landlocked economies with consequently reduced opportunities has no parallel in other regions. However, actions at the country, regional and international level would each be improved by recognizing the distinctiveness of the opportunities and problems that Africa faces. 


\section{References}

Adam, Christopher and Stephen O’Connell (1999), “Aid, Taxation and Development in Sub-Saharan Africa,” Economics and Politics 11(3), November: 225-54.

Acemoglu, Daron, Simon Johnson and James Robinson (2001), "The Colonial Origins of Comparative Development: An Empirical Investigation,” American Economic Review 91(5) December: 1369-1401.

Alesina, Alberto and Eliana La Ferrara (2004), "Ethnic Diversity and Economic Performance,” NBER Working Paper 10313.

Collier, Paul and Anke Hoeffler (2005) “Democracy and Resource Rents”, CSAE, Department of Economics, Oxford University.

Collier, Paul (2000), “Ethnicity, Politics and Economic Performance,” Economics and Politics 12(3), November: 225-45.

Gallup, J. and J. Sachs (1997), “Geography and economic growth,” In B. Plescovic and J. Stiglitz, eds, Proceedings of the World Bank Conference on Development Economics (Washington, DC, The World Bank).

Lal, Deepak (1999), “Foreign Aid: An Idea Whose Time Has Gone,” in his Unfinished Business, India in the World Economy (Oxford: Oxford University Press).

Masters, William and Margaret McMillan (2001), "Climate and Scale in Economic Growth,” Journal of Economic Growth 6(3), September.

Miguel, E., S. Satyanath and E. Sergenti, (2004) "Economic Shocks and Civil Conflict: An Instrumental Variables Approach,” Journal of Political Economy, 112(4), 725-753

Sachs, Jeffrey et al (2004), “Africa’s Poverty Trap,” Brookings Papers on Economic Activity 1: 117-240.

Tirole, Jean (1996), “A Theory of Collective Reputations (with Applications to the Persistence of Corruption and to Firm Quality)," Review of Economic Studies 63(1), January: 1-22.

Wood, Adrian (2003), “Could Africa be like America?”, in Boris Pleskovic and Nicholas Stern (eds.) Annual World Bank Conference on Development Economics, 2003, Oxford University Press, New York. 
Table A1. Global sample for growth in real GDP per capita.

\begin{tabular}{|c|c|c|c|c|c|}
\hline Country & In39 & In35 & $\begin{array}{r}\text { Population, } \\
1990 \\
\text { (million) }\end{array}$ & $\begin{array}{r}\text { Average } \\
\text { growth, } \\
1960-2000 \\
\text { or available } \\
\text { years }\end{array}$ & $\begin{array}{r}\text { First year } \\
\text { Resource- } \\
\text { Rich }\end{array}$ \\
\hline \multicolumn{6}{|l|}{ SSA: Coastal } \\
\hline Benin & 1 & 1 & 4.71 & 0.63 & . \\
\hline Cape Verde & 1 & 1 & 0.34 & 3.43 & . \\
\hline Comoros & 1 & 1 & 0.43 & -0.18 & . \\
\hline Cote d'Ivoire & 1 & 1 & 11.80 & 0.57 & . \\
\hline Gambia, The & 1 & 1 & 0.93 & 0.92 & . \\
\hline Ghana & 1 & 1 & 15.14 & -0.21 & . \\
\hline Guinea-Bissau & 1 & 1 & 0.95 & -0.58 & . \\
\hline Kenya & 1 & 1 & 23.35 & 1.23 & . \\
\hline Madagascar & 1 & 1 & 11.63 & -1.11 & . \\
\hline Mauritius & 1 & 1 & 1.06 & 3.70 & . \\
\hline Mozambique & 1 & 1 & 14.15 & -0.38 & . \\
\hline Senegal & 1 & 1 & 7.33 & -0.24 & . \\
\hline Seychelles & 1 & 1 & 0.07 & 2.35 & . \\
\hline South Africa & 1 & 1 & 35.20 & 0.88 & . \\
\hline Tanzania & 1 & 1 & 25.47 & 1.83 & . \\
\hline Togo & 1 & 1 & 3.45 & 0.86 & . \\
\hline Djibouti & 0 & 0 & 0.47 & -4.80 & . \\
\hline Eritrea & 0 & 0 & 3.14 & 2.48 & . \\
\hline Sao Tome and Principe & 0 & 0 & 0.12 & -1.06 & . \\
\hline Somalia & 0 & 0 & 7.16 & & . \\
\hline \multicolumn{6}{|l|}{ SSA: Landlocked } \\
\hline Burkina Faso & 1 & 1 & 8.88 & 1.25 & . \\
\hline Burundi & 1 & 1 & 5.46 & 0.20 & . \\
\hline Central African Republic & 1 & 1 & 2.94 & -0.75 & . \\
\hline Chad & 1 & 1 & 5.75 & -0.72 & . \\
\hline Congo, Dem. Rep. & 1 & 1 & 37.00 & -3.35 & \\
\hline Ethiopia & 1 & 1 & 51.18 & 0.41 & $1994^{\dagger}$ \\
\hline Lesotho & 1 & 1 & 1.68 & 3.57 & . \\
\hline Malawi & 1 & 1 & 8.51 & 1.36 & . \\
\hline Mali & 1 & 1 & 8.46 & -0.27 & . \\
\hline Niger & 1 & 1 & 7.71 & -1.65 & . \\
\hline Rwanda & 1 & 1 & 6.94 & -0.33 & . \\
\hline Sudan & 1 & 1 & 24.82 & 0.75 & . \\
\hline Uganda & 1 & 1 & 16.33 & 1.40 & . \\
\hline Zimbabwe & 1 & 1 & 10.24 & 0.71 & \\
\hline \multicolumn{6}{|l|}{ SSA: Resource-rich } \\
\hline Angola & 1 & 1 & 9.57 & -1.23 & 1974 \\
\hline Botswana & 1 & 1 & 1.28 & 6.33 & 1970 \\
\hline Cameroon & 1 & 1 & 11.61 & 0.66 & 1979 \\
\hline Congo, Rep. & 1 & 1 & 2.23 & 1.33 & 1974 \\
\hline Equatorial Guinea & 1 & 1 & 0.35 & 2.21 & 1996 \\
\hline
\end{tabular}


Table A1, continued

\begin{tabular}{|c|c|c|c|c|c|}
\hline Country & In39 & In35 & $\begin{array}{r}\text { Population, } \\
1990 \\
\text { (million) }\end{array}$ & $\begin{array}{r}\text { Average } \\
\text { growth, } \\
1960-2000\end{array}$ & $\begin{array}{r}\text { First year } \\
\text { Resource- } \\
\text { Rich } \\
\end{array}$ \\
\hline \multicolumn{6}{|l|}{ SSA Resource-rich, cont'd } \\
\hline Gabon & 1 & 1 & 0.94 & 2.21 & 1960 \\
\hline Guinea & 1 & 1 & 5.76 & 0.02 & 1974 \\
\hline Liberia & 1 & 1 & 2.43 & -3.49 & 1960 \\
\hline Mauritania & 1 & 1 & 1.99 & 1.30 & 1960 \\
\hline Namibia & 1 & 1 & 1.38 & 0.62 & 1979 \\
\hline Nigeria & 1 & 1 & 96.20 & 0.32 & 1971 \\
\hline Sierra Leone & 1 & 1 & 4.00 & -1.36 & 1960 \\
\hline Zambia & 1 & 1 & 7.78 & -1.25 & 1960 \\
\hline Swaziland & 0 & 0 & 0.77 & 2.03 & 1960 \\
\hline \multicolumn{6}{|l|}{ LAC: Coastal } \\
\hline Argentina & 1 & 1 & 32.53 & 0.95 & . \\
\hline Bahamas, The & 1 & 1 & 0.26 & 1.33 & . \\
\hline Barbados & 1 & 1 & 0.26 & 2.67 & . \\
\hline Belize & 1 & 1 & 0.19 & 2.91 & . \\
\hline Brazil & 1 & 1 & 147.96 & 2.44 & . \\
\hline Colombia & 1 & 1 & 34.97 & 1.82 & . \\
\hline Costa Rica & 1 & 1 & 3.05 & 1.76 & . \\
\hline Dominican Republic & 1 & 1 & 7.06 & 2.75 & . \\
\hline El Salvador & 1 & 1 & 5.11 & 0.74 & . \\
\hline Guatemala & 1 & 1 & 8.75 & 1.30 & . \\
\hline Haiti & 1 & 1 & 6.47 & -0.99 & . \\
\hline Honduras & 1 & 1 & 4.87 & 0.82 & . \\
\hline Jamaica & 1 & 1 & 2.39 & 0.54 & . \\
\hline Mexico & 1 & 1 & 83.23 & 2.11 & . \\
\hline Nicaragua & 1 & 1 & 3.82 & -0.87 & . \\
\hline Panama & 1 & 1 & 2.40 & 2.02 & . \\
\hline Peru & 1 & 1 & 21.57 & 0.56 & . \\
\hline Puerto Rico & 1 & 1 & 3.54 & 3.62 & . \\
\hline St Vincent \& Grenadines & 1 & 1 & 0.11 & 4.79 & . \\
\hline Uruguay & 1 & 1 & 3.11 & 1.14 & . \\
\hline Antigua and Barbuda & 0 & 0 & 0.06 & 4.40 & . \\
\hline Bermuda & 0 & 0 & & & . \\
\hline Cuba & 0 & 0 & 10.63 & -2.45 & . \\
\hline Dominica & 0 & 0 & 0.07 & 3.17 & . \\
\hline Grenada & 0 & 0 & 0.09 & 4.00 & . \\
\hline St. Kitts and Nevis & 0 & 0 & 0.04 & 5.08 & . \\
\hline St. Lucia & 0 & 0 & 0.13 & 3.22 & \\
\hline \multicolumn{6}{|l|}{ LAC: Landlocked } \\
\hline Paraguay & 1 & 1 & 4.15 & 1.62 & \\
\hline \multicolumn{6}{|l|}{ LAC: Resource-rich } \\
\hline Bolivia & 1 & 1 & 6.57 & 0.35 & 1970 \\
\hline Chile & 1 & 1 & 13.10 & 2.48 & 1970 \\
\hline Ecuador & 1 & 1 & 10.26 & 1.52 & 1974 \\
\hline
\end{tabular}


Table A1, continued.

\begin{tabular}{|c|c|c|c|c|c|}
\hline Country & In39 & In35 & $\begin{array}{r}\text { Popula- } \\
\text { tion,1990 } \\
\text { (million) }\end{array}$ & $\begin{array}{r}\text { Average } \\
\text { growth, } \\
1960-2000\end{array}$ & $\begin{array}{r}\text { First year } \\
\text { Resource- } \\
\text { Rich }\end{array}$ \\
\hline \multicolumn{6}{|l|}{ SASIA: Coastal } \\
\hline Guyana & 1 & 1 & 0.73 & 0.81 & 1960 \\
\hline Trinidad and Tobago & 1 & 1 & 1.22 & 2.59 & 1960 \\
\hline Venezuela, RB & 1 & 1 & 19.50 & -0.30 & 1960 \\
\hline Suriname & 0 & 0 & 0.40 & 0.60 & 1960 \\
\hline Bangladesh & 1 & 1 & 110.03 & 1.36 & . \\
\hline India & 1 & 1 & 849.52 & 2.30 & . \\
\hline Pakistan & 1 & 1 & 107.98 & 2.62 & . \\
\hline Sri Lanka & 1 & 1 & 16.27 & 2.88 & \\
\hline \multicolumn{6}{|l|}{ SASIA: Landlocked } \\
\hline Nepal & 1 & 1 & 18.14 & 1.38 & . \\
\hline Bhutan & 0 & 0 & 0.60 & 4.16 & \\
\hline \multicolumn{6}{|l|}{$\begin{array}{l}\text { SASIA: } \text { Resource-rich } \\
<\text { no cases }>\end{array}$} \\
\hline \multicolumn{6}{|l|}{ EAP: Coastal } \\
\hline China & 1 & 1 & 1135.19 & 5.42 & . \\
\hline Fiji & 1 & 1 & 0.74 & 1.66 & . \\
\hline Hong Kong, China & 1 & 1 & 5.70 & 5.26 & . \\
\hline Korea, Rep. & 1 & 1 & 42.87 & 5.75 & . \\
\hline Philippines & 1 & 1 & 61.04 & 1.16 & . \\
\hline Singapore & 1 & 1 & 3.05 & 5.92 & . \\
\hline Taiwan, China & 1 & 1 & 20.23 & 6.37 & . \\
\hline Thailand & 1 & 1 & 55.60 & 4.51 & . \\
\hline Cambodia & 0 & 0 & 9.15 & 2.33 & . \\
\hline Macao, China & 0 & 0 & 0.37 & 2.18 & . \\
\hline Vietnam & 0 & 0 & 66.20 & 4.33 & \\
\hline \multicolumn{6}{|l|}{ EAP: Landlocked } \\
\hline Lao PDR & 0 & 0 & 4.13 & 2.88 & . \\
\hline Mongolia & 0 & 0 & 2.11 & 0.52 & \\
\hline \multicolumn{6}{|l|}{ EAP: Resource-rich } \\
\hline Indonesia & 1 & 1 & 178.23 & 3.51 & 1970 \\
\hline Malaysia & 1 & 1 & 18.20 & 3.98 & 1976 \\
\hline Papua New Guinea & 1 & 1 & 3.98 & 1.30 & 1972 \\
\hline \multicolumn{6}{|l|}{ MENAT: Coastal } \\
\hline Cyprus & 1 & 1 & 0.68 & 4.40 & . \\
\hline Egypt, Arab Rep. & 1 & 1 & 52.44 & 3.05 & . \\
\hline Israel & 1 & 1 & 4.66 & 2.94 & . \\
\hline Jordan & 1 & 1 & 3.17 & 1.15 & . \\
\hline Malta & 1 & 1 & 0.36 & 5.42 & . \\
\hline Morocco & 1 & 1 & 24.04 & 1.69 & . \\
\hline Turkey & 1 & 1 & 56.15 & 2.29 & . \\
\hline Lebanon & 0 & 0 & 3.63 & 1.34 & \\
\hline
\end{tabular}

MENAT: Landlocked

$<$ no cases $>$ 
Table A1, continued.

\begin{tabular}{|c|c|c|c|c|c|}
\hline Country & In39 & In35 & $\begin{array}{r}\text { Popula- } \\
\text { tion,1990 } \\
\text { (million) }\end{array}$ & $\begin{array}{r}\text { Average } \\
\text { growth, } \\
1960-2000\end{array}$ & $\begin{array}{r}\text { First year } \\
\text { Resource- } \\
\text { Rich }\end{array}$ \\
\hline \multicolumn{6}{|l|}{ MENAT: Resource-rich } \\
\hline Algeria & 1 & 1 & 25.02 & 0.86 & 1960 \\
\hline Iran, Islamic Rep. & 1 & 1 & 54.40 & 1.50 & 1960 \\
\hline Oman & 1 & 1 & 1.63 & 5.35 & 1967 \\
\hline Saudi Arabia & 1 & 1 & 15.80 & 1.46 & 1960 \\
\hline Syrian Arab Republic & 1 & 1 & 12.12 & 2.28 & 1974 \\
\hline Tunisia & 1 & 1 & 8.15 & 3.02 & 1974 \\
\hline Kuwait & 0 & 1 & 2.13 & -3.70 & 1960 \\
\hline Bahrain & 0 & 0 & 0.50 & 0.14 & 1960 \\
\hline Iraq & 0 & 0 & 18.08 & . & 1960 \\
\hline Qatar & 0 & 0 & 0.49 & . & 1960 \\
\hline United Arab Emirates & 0 & 0 & 1.84 & -3.90 & 1973 \\
\hline Yemen, Rep. & 0 & 0 & 11.88 & 1.51 & 1990 \\
\hline \multicolumn{6}{|l|}{ EEFSU: Coastal } \\
\hline Romania & 1 & 1 & 23.21 & 1.94 & \\
\hline Georgia & 0 & 1 & 5.46 & -0.80 & \\
\hline Latvia & 0 & 1 & 2.67 & 1.82 & \\
\hline Russian Federation & 0 & 1 & 148.29 & 1.54 & . \\
\hline Bulgaria & 0 & 0 & 8.72 & 0.73 & . \\
\hline Croatia & 0 & 0 & 4.77 & -0.55 & \\
\hline Estonia & 0 & 0 & 1.57 & 0.49 & \\
\hline Lithuania & 0 & 0 & 3.70 & -3.28 & \\
\hline Poland & 0 & 0 & 38.12 & 2.65 & . \\
\hline Slovenia & 0 & 0 & 2.00 & 1.88 & \\
\hline Ukraine & 0 & 0 & 51.89 & -6.17 & . \\
\hline Yugoslavia, Fed. Rep. & 0 & 0 & 10.53 & & \\
\hline \multicolumn{6}{|l|}{ EEFSU: Landlocked } \\
\hline Hungary & 1 & 1 & 10.36 & 3.17 & \\
\hline Armenia & 0 & 0 & 3.55 & -4.58 & \\
\hline Belarus & 0 & 0 & 10.19 & -1.02 & \\
\hline Czech Republic & 0 & 0 & 10.36 & 0.21 & • \\
\hline Kyrgyz Republic & 0 & 0 & 4.42 & -2.53 & \\
\hline Macedonia, FYR & 0 & 0 & 1.90 & -0.78 & . \\
\hline Moldova & 0 & 0 & 4.36 & -4.22 & \\
\hline Slovak Republic & 0 & 0 & 5.28 & 0.58 & . \\
\hline Tajikistan & 0 & 0 & 5.30 & -7.92 & \\
\hline \multicolumn{6}{|l|}{ EEFSU: Resource-rich } \\
\hline Albania & 0 & 0 & 3.28 & 0.37 & 1984 \\
\hline Azerbaijan & 0 & 0 & 7.16 & -4.41 & 1992 \\
\hline Kazakhstan & 0 & 0 & 16.35 & -3.06 & 1990 \\
\hline Turkmenistan & 0 & 0 & 3.67 & -4.97 & 1993 \\
\hline Uzbekistan & 0 & 0 & 20.51 & -1.16 & 1991 \\
\hline \multicolumn{6}{|l|}{ INDUST: Coastal } \\
\hline Australia & 1 & 1 & 17.07 & 2.13 & \\
\hline Belgium & 1 & 1 & 9.97 & 2.75 & \\
\hline
\end{tabular}


Table A1, continued.

\begin{tabular}{|c|c|c|c|c|c|}
\hline Country & In39 & In35 & $\begin{array}{r}\text { Population, } \\
1990 \\
\text { (million) } \\
\end{array}$ & $\begin{array}{r}\text { Average } \\
\text { growth, } \\
1960-2000 \\
\end{array}$ & $\begin{array}{r}\text { First year } \\
\text { Resource- } \\
\text { Rich }\end{array}$ \\
\hline \multicolumn{6}{|c|}{ INDUST: Coastal (cont'd) } \\
\hline Canada & 1 & 1 & 27.79 & 2.31 & \\
\hline Cyprus & 1 & 1 & 0.68 & 4.40 & \\
\hline Denmark & 1 & 1 & 5.14 & 2.15 & \\
\hline Finland & 1 & 1 & 4.99 & 2.97 & \\
\hline France & 1 & 1 & 56.74 & 2.61 & \\
\hline Greece & 1 & 1 & 10.16 & 3.11 & \\
\hline Iceland & 1 & 1 & 0.25 & 2.83 & . \\
\hline Ireland & 1 & 1 & 3.51 & 4.10 & . \\
\hline Italy & 1 & 1 & 56.72 & 2.88 & \\
\hline Japan & 1 & 1 & 123.54 & 4.18 & \\
\hline Netherlands & 1 & 1 & 14.95 & 2.41 & . \\
\hline New Zealand & 1 & 1 & 3.44 & 1.28 & . \\
\hline Norway & 1 & 1 & 4.24 & 3.04 & \\
\hline Portugal & 1 & 1 & 9.90 & 3.90 & \\
\hline Spain & 1 & 1 & 38.84 & 3.34 & \\
\hline Sweden & 1 & 1 & 8.56 & 2.17 & \\
\hline United Kingdom & 1 & 1 & 57.56 & 2.12 & . \\
\hline United States & 1 & 1 & 249.44 & 2.21 & . \\
\hline Germany & 0 & 0 & 79.43 & 1.99 & \\
\hline \multicolumn{6}{|c|}{ INDUST: Landlocked } \\
\hline Austria & 1 & 1 & 7.73 & 2.85 & \\
\hline Luxembourg & 1 & 1 & 0.38 & 3.20 & \\
\hline Switzerland & 1 & 1 & 6.71 & 1.44 & \\
\hline
\end{tabular}

INDUST: Resource-rich

$<$ no cases $>$

Notes:

${ }^{\dagger}$ Ethiopia became landlocked in 1994 with the independence of Eritrea.

*Growth rates are calculated for available years. In39 means at least 39 of 40 annual growth observations 1961-2000 available. In35 means at least 35 of 40 annual growth observations 1961-2000 available.

Most of our empirical work excludes the industrial countries and also excludes any country without at least 39 observations. 
Table A2. Syndrome classification.

\begin{tabular}{|c|c|c|c|c|c|c|c|c|}
\hline \multirow{2}{*}{$\begin{array}{l}\text { Country }(\text { bold }= \\
\text { case study country) }\end{array}$} & \multicolumn{2}{|c|}{$\begin{array}{l}\text { REGULATORY } \\
\text { SYNDROMES }\end{array}$} & \multicolumn{2}{|c|}{$\begin{array}{l}\text { REDISTRIBUTIVE } \\
\text { SYNDROMES }\end{array}$} & \multicolumn{2}{|c|}{$\begin{array}{l}\text { INTERTEMPORAL } \\
\text { SYNDROMES }\end{array}$} & \multirow{2}{*}{$\begin{array}{l}\text { STATE } \\
\text { BREAK- } \\
\text { DOWN }\end{array}$} & \multirow{2}{*}{$\begin{array}{l}\text { SYNDROME } \\
\text { FREE }\end{array}$} \\
\hline & $\begin{array}{c}\text { Soft } \\
\text { controls }\end{array}$ & $\begin{array}{c}\text { Hard } \\
\text { controls }\end{array}$ & Regional & Looting & $\begin{array}{c}\text { Unsustianable } \\
\text { spending }\end{array}$ & $\begin{array}{c}\text { Anticipated } \\
\text { Redistribution }\end{array}$ & & \\
\hline Angola & $91-05$ & $75-90$ & $75-05$ & $90-05$ & $94-05$ & $72-75$ & $75-02$ & $60-71$ \\
\hline Benin & $\begin{array}{l}60-74 \\
04-05 \\
\end{array}$ & $75-89$ & -- & -- & -- & -- & -- & $90-03$ \\
\hline Botswana & -- & -- & -- & -- & -- & -- & -- & $60-05$ \\
\hline Burkina Faso & $60-82$ & $83-90$ & -- & -- & -- & -- & -- & $91-05$ \\
\hline Burundi & $72-88$ & -- & $72-88$ & $72-88$ & $72-88$ & -- & $\begin{array}{l}60-72, \\
88-05\end{array}$ & -- \\
\hline Cameroon & $60-77$ & -- & -- & -- & $78-93$ & -- & -- & $94-05$ \\
\hline Cape Verde & $75-91$ & -- & -- & -- & -- & $74-75$ & -- & $\begin{array}{l}60-73 \\
92-05\end{array}$ \\
\hline C. A. R. & $65-05$ & -- & -- & $65-79$ & -- & -- & $96-03$ & $60-64$ \\
\hline Chad & $60-05$ & -- & $60-90$ & -- & -- & -- & $79-84$ & -- \\
\hline Comoros & $79-05$ & $76-78$ & 79-05 & $79-89$ & -- & -- & $\begin{array}{l}76-78, \\
90-05\end{array}$ & $60-75$ \\
\hline Congo, Dem. Rep. & -- & -- & $65-73$ & $73-97$ & -- & -- & $\begin{array}{l}\text { 60-65, } \\
96-05\end{array}$ & -- \\
\hline Congo & $63-68$ & 69-91 & $69-91$ & -- & $82-91$ & -- & 93, 97, 02 & $\begin{array}{c}60-62,94- \\
96,98-01,03- \\
05\end{array}$ \\
\hline
\end{tabular}


Table A2, Syndrome classification, continued

\begin{tabular}{|c|c|c|c|c|c|c|c|c|}
\hline \multirow{2}{*}{$\begin{array}{l}\text { Country } \\
\text { (bold = case study) }\end{array}$} & \multicolumn{2}{|c|}{$\begin{array}{c}\text { REGULATORY } \\
\text { SYNDROMES }\end{array}$} & \multicolumn{2}{|c|}{$\begin{array}{l}\text { REDISTRIBUTIVE } \\
\text { SYNDROMES }\end{array}$} & \multicolumn{2}{|c|}{$\begin{array}{c}\text { INTERTEMPORAL } \\
\text { SYNDROMES }\end{array}$} & \multirow{2}{*}{$\begin{array}{c}\text { STATE } \\
\text { BREAK- } \\
\text { DOWN }\end{array}$} & \multirow{2}{*}{$\begin{array}{l}\text { SYNDROME } \\
\text { FREE }\end{array}$} \\
\hline & $\begin{array}{c}\text { Soft } \\
\text { controls }\end{array}$ & $\begin{array}{c}\text { Hard } \\
\text { controls }\end{array}$ & Regional & Looting & $\begin{array}{c}\text { Unsustianable } \\
\text { spending }\end{array}$ & $\begin{array}{c}\text { Anticipated } \\
\text { Redistribution }\end{array}$ & & \\
\hline Cote d'Ivoire & $80-89$ & -- & -- & $70-90$ & -- & -- & -- & $\begin{array}{l}60-69 \\
91-00\end{array}$ \\
\hline Djibouti & -- & -- & $77-05$ & -- & -- & -- & $91-00$ & $60-76$ \\
\hline Equatorial Guinea & -- & -- & -- & $68-05$ & -- & -- & $68-79$ & $60-67$ \\
\hline Eritrea & -- & $99-05$ & -- & -- & -- & -- & $99-00$ & $93-98$ \\
\hline Ethiopia & -- & $74-91$ & -- & -- & -- & -- & -- & $\begin{array}{l}60-73, \\
92-05 \\
\end{array}$ \\
\hline Gabon & $60-97$ & -- & -- & -- & -- & -- & -- & 98-05 \\
\hline Gambia, The & -- & -- & -- & -- & -- & -- & -- & $60-05$ \\
\hline Ghana & 72-78, 84 & $\begin{array}{l}60-68 \\
79-83\end{array}$ & $60-68$ & -- & -- & -- & -- & $\begin{array}{l}69-71 \\
85-05\end{array}$ \\
\hline Guinea & $\begin{array}{l}60-63 \\
78-84 \\
\end{array}$ & $64-77$ & -- & -- & $73-84$ & -- & -- & $85-05$ \\
\hline Guinea-Bissau & $74-05$ & -- & -- & -- & -- & $60-73$ & $98-05$ & -- \\
\hline Kenya & $72-90$ & -- & $\begin{array}{l}78-02, \\
03-05 \\
\end{array}$ & -- & -- & -- & -- & $60-71$ \\
\hline Lesotho & -- & -- & -- & -- & -- & -- & -- & $60-05$ \\
\hline
\end{tabular}


Table A2, Syndrome classification, continued.

\begin{tabular}{|c|c|c|c|c|c|c|c|c|}
\hline \multirow{2}{*}{$\begin{array}{l}\text { Country } \\
\text { (bold = case study) }\end{array}$} & \multicolumn{2}{|c|}{$\begin{array}{l}\text { REGULATORY } \\
\text { SYNDROMES }\end{array}$} & \multicolumn{2}{|c|}{$\begin{array}{l}\text { REDISTRIBUTIVE } \\
\text { SYNDROMES }\end{array}$} & \multicolumn{2}{|c|}{$\begin{array}{c}\text { INTERTEMPORAL } \\
\text { SYNDROMES }\end{array}$} & \multirow{2}{*}{$\begin{array}{c}\text { STATE } \\
\text { BREAK- } \\
\text { DOWN }\end{array}$} & \multirow{2}{*}{$\begin{array}{l}\text { SYNDROME } \\
\text { FREE }\end{array}$} \\
\hline & $\begin{array}{c}\text { Soft } \\
\text { controls }\end{array}$ & $\begin{array}{c}\text { Hard } \\
\text { controls }\end{array}$ & Regional & Looting & $\begin{array}{c}\text { Unsustianable } \\
\text { spending }\end{array}$ & $\begin{array}{c}\text { Anticipated } \\
\text { Redistribution }\end{array}$ & & \\
\hline Liberia & -- & -- & $80-90$ & $97-03$ & -- & -- & $\begin{array}{l}80-97 \\
00-03\end{array}$ & $\begin{array}{c}\text { 60-79, } \\
04-05\end{array}$ \\
\hline Madagascar & $\begin{array}{l}72-75 \\
86-96\end{array}$ & $76-85$ & -- & -- & -- & $72-77$ & 02 & $\begin{array}{c}60-71, \\
97-01,03-05\end{array}$ \\
\hline Malawi & -- & -- & -- & -- & -- & -- & -- & $60-05$ \\
\hline Mali & -- & $60-68$ & -- & 68-91 & -- & -- & -- & $92-05$ \\
\hline Mauritania & $74-85$ & -- & -- & -- & -- & -- & -- & $\begin{array}{l}60-73 \\
86-05 \\
\end{array}$ \\
\hline Mauritius & $60-70$ & -- & -- & -- & -- & -- & -- & 71-05 \\
\hline Mozambique & $60-76$ & $77-86$ & -- & $74-76$ & -- & $69-74$ & $74-91$ & $92-05$ \\
\hline Namibia & -- & -- & -- & -- & -- & $75-89$ & -- & $\begin{array}{l}60-74 \\
90-05 \\
\end{array}$ \\
\hline Niger & $60-89$ & -- & -- & -- & 74-89 & -- & $90-99$ & 00-05 \\
\hline Nigeria & -- & 83-86 & $67-03$ & $\begin{array}{l}73-87, \\
93-98 \\
\end{array}$ & $70-87$ & -- & $66-70$ & $\begin{array}{l}60-65 \\
04-05\end{array}$ \\
\hline Rwanda & -- & -- & $73-94$ & -- & -- & -- & $93-94$ & $\begin{array}{l}\text { 60-72, } \\
95-05\end{array}$ \\
\hline $\begin{array}{l}\text { Sao Tome and } \\
\text { Principe }\end{array}$ & NA & NA & NA & NA & NA & NA & NA & NA \\
\hline
\end{tabular}


Table A2, Syndrome classification, continued.

\begin{tabular}{|c|c|c|c|c|c|c|c|c|}
\hline \multirow{2}{*}{$\begin{array}{l}\text { Country } \\
\text { (bold = case study) }\end{array}$} & \multicolumn{2}{|c|}{$\begin{array}{l}\text { REGULATORY } \\
\text { SYNDROMES }\end{array}$} & \multicolumn{2}{|c|}{$\begin{array}{l}\text { REDISTRIBUTIVE } \\
\text { SYNDROMES }\end{array}$} & \multicolumn{2}{|c|}{$\begin{array}{c}\text { INTERTEMPORAL } \\
\text { SYNDROMES }\end{array}$} & \multirow{2}{*}{$\begin{array}{c}\text { STATE } \\
\text { BREAK- } \\
\text { DOWN }\end{array}$} & \multirow{2}{*}{$\begin{array}{l}\text { SYNDROME } \\
\text { FREE }\end{array}$} \\
\hline & $\begin{array}{c}\text { Soft } \\
\text { controls }\end{array}$ & $\begin{array}{c}\text { Hard } \\
\text { controls }\end{array}$ & Regional & Looting & $\begin{array}{c}\text { Unsustianable } \\
\text { spending } \\
\end{array}$ & $\begin{array}{c}\text { Anticipated } \\
\text { Redistribution } \\
\end{array}$ & & \\
\hline Senegal & $60-93$ & -- & -- & -- & $74-78$ & -- & -- & $94-05$ \\
\hline Seychelles & 93-05 & $72-92$ & -- & -- & -- & -- & -- & $60-71$ \\
\hline Sierra Leone & -- & 70-89 & $70-00$ & $70-00$ & -- & -- & $\begin{array}{l}67-69 \\
90-00 \\
\end{array}$ & $\begin{array}{l}60-66, \\
01-05\end{array}$ \\
\hline South Africa & $60-91$ & -- & $60-91$ & -- & -- & $77-93$ & -- & $94-05$ \\
\hline Sudan & 70-89 & -- & -- & -- & -- & -- & $\begin{array}{l}62-72, \\
85-05\end{array}$ & $60-61$ \\
\hline Swaziland & -- & -- & -- & -- & -- & -- & -- & $60-05$ \\
\hline Tanzania & $86-94$ & 70-85 & -- & -- & -- & -- & -- & $\begin{array}{l}\text { 60-69, } \\
95-05 \\
\end{array}$ \\
\hline Togo & 74-05 & -- & $75-00$ & $94-05$ & $74-89$ & $94-00$ & $91-93$ & $60-73$ \\
\hline Uganda & $\begin{array}{l}60-67 \\
71-91 \\
\end{array}$ & $68-70$ & $66-70$ & $71-79$ & -- & -- & 79-86 & $92-05$ \\
\hline Zambia & $68-91$ & -- & -- & -- & 73-89 & -- & -- & $\begin{array}{l}60-67 \\
92-05\end{array}$ \\
\hline Zimbabwe & $65-99$ & $00-05$ & -- & $98-05$ & -- & $\begin{array}{l}76-80 \\
91-97 \\
\end{array}$ & $76-80$ & $60-64$ \\
\hline
\end{tabular}

Source: Judgmental classification by project editors and country authors. NA denotes inadequate basis for classification. 
Table A3. Neighbor effects on growth (continuation of text table 20).

\begin{tabular}{|c|c|c|c|}
\hline \multirow{2}{*}{ Variable } & \multicolumn{3}{|c|}{ LAD regressions } \\
\hline & (7) & (8) & (9) \\
\hline \multirow[t]{2}{*}{ Landlocked (LL) } & $-0.535 * * *$ & $-0.491 * *$ & $-1.182 * * *$ \\
\hline & 0.201 & 0.204 & 0.286 \\
\hline \multirow[t]{2}{*}{ Resource-rich (RR) } & $-0.597 * * *$ & $-0.601 * *$ & $-0.716 * * *$ \\
\hline & 0.217 & 0.256 & 0.195 \\
\hline \multirow[t]{2}{*}{ Island } & $1.465 * * *$ & $1.481^{* * *}$ & $1.350 * * *$ \\
\hline & 0.089 & 0.231 & 0.174 \\
\hline \multirow[t]{2}{*}{ Neighbor growth } & $0.319 * * *$ & $0.321 * * *$ & $0.280 * * *$ \\
\hline & 0.036 & 0.042 & 0.032 \\
\hline \multirow[t]{2}{*}{ CO*SSA } & $-1.143^{* * *}$ & $-1.136 * * *$ & $-1.219 * * *$ \\
\hline & 0.218 & 0.295 & 0.231 \\
\hline \multirow[t]{2}{*}{$\mathrm{LL} * \mathrm{SSA}$} & $-0.950 * * *$ & $-1.012 * *$ & -0.388 \\
\hline & 0.332 & 0.423 & 0.362 \\
\hline \multirow[t]{2}{*}{$\mathrm{RR} * \mathrm{SSA}$} & -0.204 & -0.201 & -0.179 \\
\hline & 0.289 & 0.219 & 0.283 \\
\hline \multirow[t]{2}{*}{ Island*SSA } & $-1.122 * * *$ & $-1.084 * *$ & $-0.964 *$ \\
\hline & 0.41 & 0.479 & 0.54 \\
\hline \multirow[t]{2}{*}{ Neighbor growth*LL } & -- & -- & $0.201^{* * *}$ \\
\hline & & & 0.077 \\
\hline \multirow[t]{2}{*}{ Neighbor growth*RR } & -- & -- & 0.04 \\
\hline & & & 0.083 \\
\hline \multirow[t]{2}{*}{ Nbr growth*CO*SSA } & -- & $-0.213 * * *$ & $-0.181 * *$ \\
\hline & & 0.075 & 0.072 \\
\hline \multirow[t]{2}{*}{ Nbr growth*LL*SSA } & -- & 0.032 & -0.123 \\
\hline & & 0.073 & 0.092 \\
\hline \multirow[t]{2}{*}{ Nbr growth*RR*SSA } & -- & $-0.282 * * *$ & $-0.279 * * *$ \\
\hline & & 0.079 & 0.099 \\
\hline \multirow[t]{2}{*}{ Neighbor growth*SSA } & $-0.186 * * *$ & -- & -- \\
\hline & 0.067 & & \\
\hline \multirow[t]{2}{*}{ Dry year } & -0.09 & -0.05 & -0.099 \\
\hline & 0.134 & 0.148 & 0.101 \\
\hline $\mathrm{N}$ & 5620 & 5620 & 5620 \\
\hline Pseudo-R2 & 0.0626 & 0.0639 & 0.0647 \\
\hline
\end{tabular}

legend: ${ }^{*} \mathrm{p}<.1 ;{ }^{* *} \mathrm{p}<.05 ;{ }^{* * *} \mathrm{p}<.01$. Bootstrapped standard errors. All regressions include a full set of year effects. 